\title{
PROVIDER PERCEPTIONS OF TREATMENT OPTIONS FOR IMMATURE PERMANENT TEETH
}

\author{
Alison St. Paul
}

A thesis submitted to the faculty of the University of North Carolina at Chapel Hill in partial fulfillment of the requirements for the degree of Master of Science in the School of Dentistry (Endodontics).

Chapel Hill

2015

Approved by:

Asma Khan

Ceib Phillips

Jessica Lee 
(C)2016

Alison St. Paul

ALL RIGHTS RESERVED 


\begin{abstract}
Alison St. Paul: Provider Perceptions of Treatment Options for Immature Permanent Teeth

(Under the direction of Asma Khan)
\end{abstract}

The purpose of this study was to survey endodontists and pediatric dentists on the use of apexification and regenerative endodontics for the treatment of immature permanent teeth. We surveyed pediatric dentists $(\mathrm{n}=1941)$ and endodontists $(\mathrm{n}=1615)$ in four geographically and demographically diverse states- North Carolina, New York, Texas and California. The surveys were created using qualtrics and teleform and distributed using the Salant and Dillman method. Data was analyzed using chi square, linear and multinominal regression. 574 Endodontists (32.9\% success rate) and 526 pediatric dentists (27.1\% response rate) responded to the surveys. Both endodontists and pediatric dentists reported that they occasionally to rarely diagnose and treat patients with pulpal necrosis. Of the $43.3 \%$ of pediatric dentists who do not refer, $24 \%$ indicated that they perform only apexification. Predictability of outcome $(\mathrm{p}<.01)$, continued root development $(\mathrm{p}=0.01)$ and apical closure $(\mathrm{p}=0.01)$ significantly influence the decision to choose one treatment option for both specialties. 
To my mentor and my committee, I couldn't have done this without all of you Thank you for all of your respective support along the way. 


\section{ACKNOWLEDGEMENTS}

This work would not have been possible without the help of these individuals:

Dr. Asma Khan, my research mentor, who worked with me diligently and believed in the value of this project.

Dr. Ceib Phillips one of my research committee members, for her help with my grant application and statistical analysis.

Dr. Jessica Lee, my third research committee member for her continued support throughout this project.

Dr. Timothy Wright for his help in obtaining funding for my project. Without this, my research would not be possible.

The staff at the UNC Orthodontics Research Lab for their assistance with survey preparation, scanning, and statistics.

The predental UNC students Janki, Katherine, Olivia, Adam, Ian, Olivia Lee, Bethany, Collin, Thurston, Elizabeth, Erin and Callie for their help with mailing all the surveys.

The American Association of Endodontists Foundation, The Tarheel Endodontic Association and the UNC Department of Endodontics for their financial support. 


\section{TABLE OF CONTENTS}

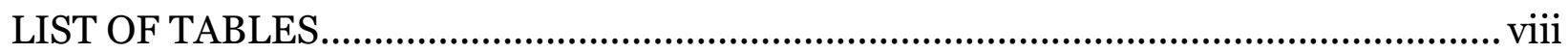

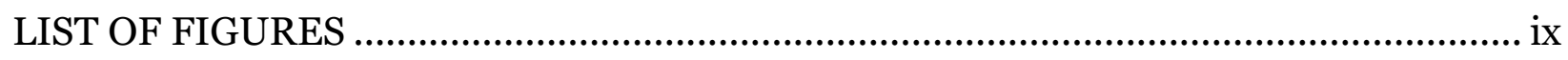

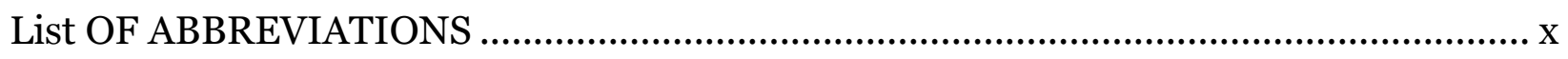

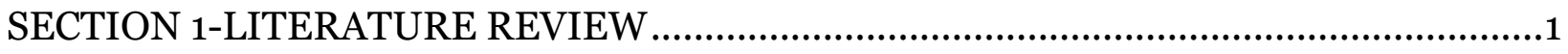

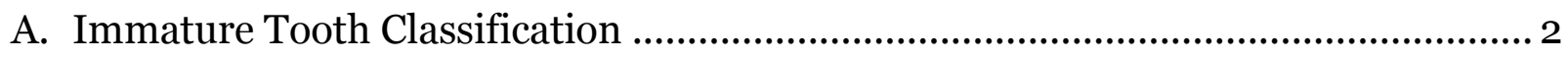

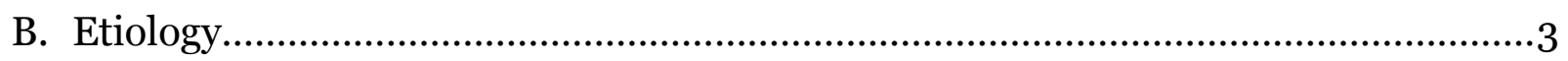

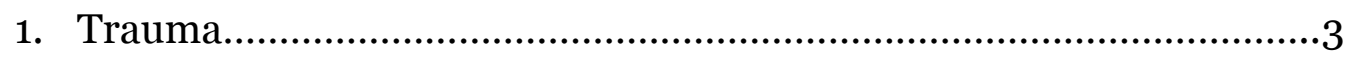

2. Caries............................................................................................

C. Treatment of Immature Teeth with Pulpal Pathologies..............................................5

1. Vital Tooth Therapy..........................................................................

a) Pulp Capping: Direct/Indirect................................................6

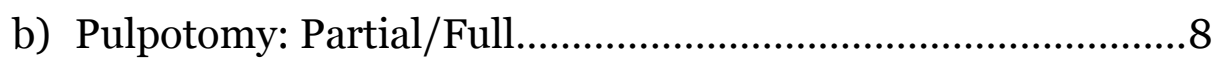

2. Non Vital Tooth Therapy.................................................................10

a) Apexification................................................................................

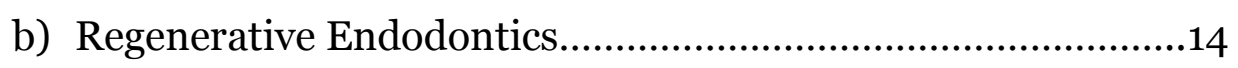

3. Apexification vs Regeneration...........................................................19

4. Published Surveys on Regenerative Endodontics...............................20

5. References.......................................................................................23

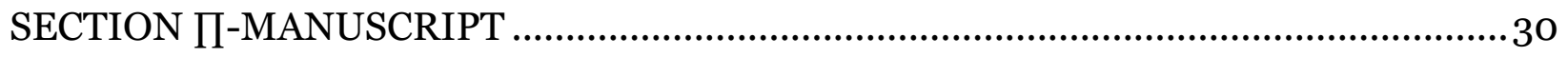




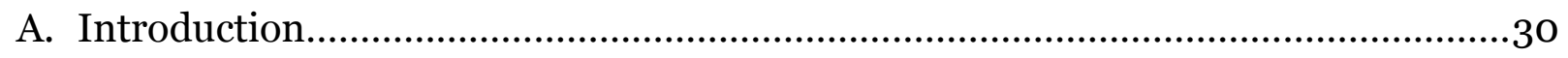

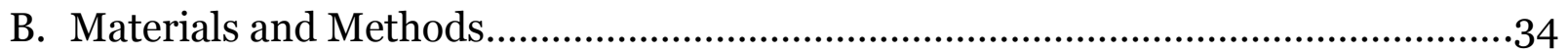

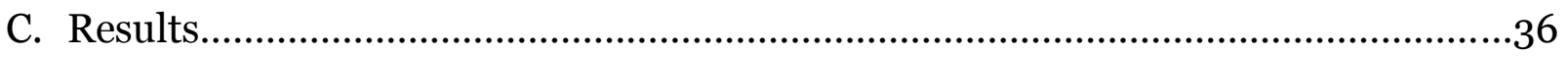

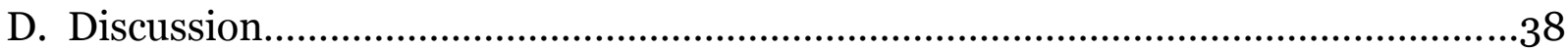

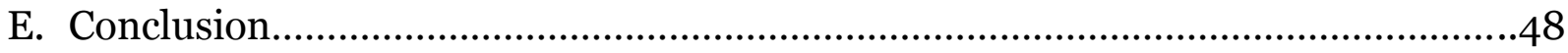

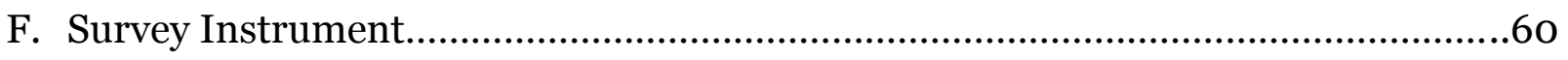

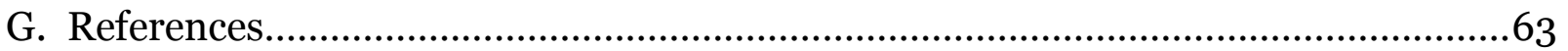

SECTION Ш-CONCLUSION.................................................................... 67 


\section{LIST OF TABLES}

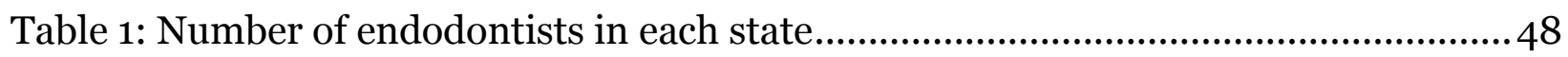

Table 2: Respondent demographics............................................................................50

Table 3: Respondent percentages - conditions, method

(treatment performed),frequency of pulpal necrosis

and education (Grad course taught and CE)

Table 4: Preferable choice of treatment....................................................................... 52

Table 5: Chi-square- Comparison factors and associated variables .... 


\section{LIST OF FIGURES}

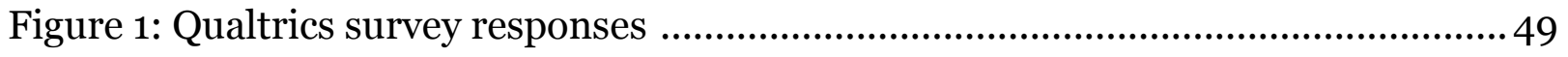




\section{LIST OF ABBREVIATIONS}

AAE

CA

CE

MTA

NC

NY

TX

UNC
American Association of Endodontists

California

Continuing Education

Mineral Trioxide Aggregate

North Carolina

New York

Texas

University of North Carolina 


\section{Section 1}

\section{Literature Review}

An immature permanent tooth is a tooth with incomplete root formation and for decades these teeth have made endodontic treatment very challenging. ${ }^{[1]}$ The primary aim of endodontic treatment is the completion of chemomechanical instrumentation which reduces the microbial concentration and therefore allows the clinician to complete canal obturation. A large apical diameter in addition to short roots are some of the factors that limit the survival rate following endodontic treatment of an immature permanent tooth. Due to variations in apical size and dentinal wall thickness, an insult to an immature permanent tooth such as trauma or caries while it is still developing can halt root development thus decreasing the prognosis and tooth survival. As a result, research has shown that the management of a vital pulp is far less challenging when compared to the treatment of a non-vital pulp [2]. Extraction of an immature permanent tooth with a necrotic pulp is an option, albeit a last resort, because alternatives for tooth replacement are not ideal and implant placement is contraindicated in a child due to continued jaw growth [3]. The ideal treatment option for an immature permanent tooth whether vital or necrotic is one that achieves the goals of endodontic therapy while maintaining both form and function of the tooth. A brief review of the literature will be presented with a focus on endodontic treatment options of an immature permanent tooth and future directions in this field. 


\section{Immature Tooth Classification}

The determination of a child's dental age is made using a combination of factors such as tooth emergence and tooth formation [4]. Tooth formation supersedes tooth emergence as it is a better indicator of a tooth's maturation. The reason for this is that the emergence of a tooth occurs during a short period of time and can also be influenced by certain factors such as spacing within the dental arch and loss of primary teeth. Using tooth formation to determine a child's dental age is far less challenging because the majority of the tooth can be evaluated during an examination and time is not a limiting factor[4]. Immature permanent teeth during development have been classified both by Cvek and Moorrees based on root development. Cvek classified these teeth into five groups and Moorrees into six groups according to root length and apical diameter [5] [4]. According to the Cvek classification, teeth in group 1 have roots with wide, divergent ends with less than half of their root length. Teeth with one half to two thirds root length are placed into the second group and the third group is reserved for teeth having two thirds root development complete. The fourth and fifth groups are very similar in root length but group four teeth have an open apex. The Moorees classification is very similar to the Cvek classification with the only differences being noted in the stage one and two categories. Teeth in the initial stage have twenty five percent of their root development complete and teeth in the second stage have one-half root formation complete.

Although these two classification systems are infrequently used, they do provide a basis upon which clinicians can communicate and evaluate immature permanent teeth. This is important because it enables us as clinicians to develop treatment protocols that can both increase tooth survivability and prognosis. 


\section{Etiology}

\section{A. Trauma}

The frequency of dental trauma of the immature permanent tooth ranges from 4-66 \% in children ${ }^{[6,7]}$. Differences in the range can be attributed to the type of injury being investigated, the study population and the methodology used for data collection. In an epidemiological study of 487 children the incidence of trauma to immature permanent teeth was $22 \%$ [8]. These children were originally included in a prior study aimed at investigating the impact of injury of primary teeth to their permanent successors. Their ages ranged from 3 to 7 in the initial study and 9 to 17 in this subsequent epidemiological study. Differences in gender and age were also noted. Boys had a higher frequency of traumatic injuries compared to girls. The peak age range for trauma in boys occurred between 2-4 and 9-10 years. Most traumatic injuries for girls occurred during the peak age range of 2-3 only. This difference can be attributed to the increase in energetic activity seen in boys in the 9-10 age group [8]. In another study, a retrospective analysis of 384 patients within the age range of 7 and 65 was done to investigate preliminary factors leading to trauma, causes of trauma and post treatment complications that can occur following injury. This study included a sample size of 889 permanent teeth and authors concluded that $66 \%$ of patients with traumatized teeth were children [7]. The most traumatic injury was an avulsed immature permanent tooth which can sometimes result in post-traumatic complications such as ankylosis, resorption and necrosis. Pulpal necrosis was the most prevalent post traumatic event to occur (26.9\%) [7]. Furthermore, an analysis of treatment success and cost was done on patients who presented for treatment after a traumatic dental injury in a major trauma center ${ }^{[9]} .7,549$ patients with an average age of $13.8(0-89)$ were divided according to 
type of dental injury and tooth type. $13 \%$ of the total number of patients presenting for treatment after a traumatic dental injury occurred on an annual basis with ages ranging from 7-17. In general, most traumatic injuries occurred to maxillary anterior teeth damaging not only the dental hard tissues but that of the surrounding bone and soft tissue. Since incisors are most commonly traumatized, the lack of root development make endodontic treatment very challenging. Clinicians need to consider the potential negative impacts trauma can have on the psychological aspect of a child's life if he or she loses a central incisor at an early age ${ }^{[10]}$. The resultant effects of dental traumatic injuries are dependent on the tooth and its root development stage along with the type extent and reoccurrence of injury. Complications following a traumatic injury can be immediate or delayed, thus mandating a thorough follow up throughout the life of the individual. [11]. Endodontic treatment of a mature permanent tooth in general has been documented as being much easier when compared to the endodontic treatment of an immature permanent tooth. The explanation is that pulpal debridement is more challenging due to large apical diameters, lack of an apical stop for obturation and the higher incidence of tooth fracture due to thin dentinal walls ${ }^{[1]}$.

\section{B. Caries}

In addition to trauma, caries is another etiological factor that can lead to pulpal pathologies including irreversible pulpitis and pulpal necrosis. Published studies have documented the pulp's ability to evoke an immune response and to develop a defense mechanism. The inflammatory response has been described as being both cellular and humoral in nature ${ }^{[12]}$. Research has shown that even during the development of an initial carious front, changes are occurring in the pulp and an inflammatory response can be observed in the pulp beneath the carious layer prior to cavitation ${ }^{[13]}$. As caries 
progress and increases in proximity to the pulp, the remaining dentin thickness above the pulp and the proximity of bacteria to the pulp results in an increase in the inflammatory response. A carious front of $1.1 \mathrm{~mm}-1.5 \mathrm{~mm}$ away from the pulp has been shown to be a critical distance, which if decreased would lead to irreversible pulpal damage ${ }^{[12,14]}$. When the dentin thickness decreases resulting in a pulpal exposure, bacterial invasion is initiated via a chemotaxic response of inflammatory cells such as leukocytes and macrophages which in turn activate various complement pathways. This results in an increased concentration of complement system cells such as lymphoid cells, plasma cells and immunoglobulins in inflamed pulps compared to normal pulps [15]. Depending on the nature of activated complement, the resultant response can be either protective or injurious to the pulp [15].

\section{Treatment of Immature Teeth with Pulpal Pathologies}

Treatment options vary depending on the pulpal diagnosis. The traditional method of treating a vital pulp with apexogenesis has been shown to be very successful for the treatment of immature permanent teeth with irreversible pulpitis ${ }^{[1]}$. Pulpotomies, pulp capping whether direct or indirect are some of the procedures that help preserve pulp vitality and will be further described in detail [16]. Historically, nonvital teeth were treated with apexification prior to the completion of non-surgical root canal therapy ${ }^{[1]}$. Currently with the re-introduction of regenerative endodontics with new scientifically proven modified advanced materials and techniques, immature permanent teeth with a non-vital pulp can be successfully treated ${ }^{[17]}$.

\section{a) Vital Tooth Therapy}

The main aim of apexogenesis is to preserve the vitality of the pulp thus allowing the continued development of the root. This occurs when the viability of the Hertwig's 
epithelial sheath is sustained allowing the root to continue to develop. Preserving the pulp vitality will also allow the continuous deposition of dentin by surviving odontoblastic cells, which induce closure of the apex and create an environment that encourages the formation of a dentinal bridge, thereby allowing placement of obturation material within the closed confines of an apical seal if needed in the future ${ }^{[18]}$.

\section{Pulp Cap: Direct/ Indirect}

When gross decay is present in an immature permanent tooth and carious excavation may lead to a pulpal exposure, a pulp cap may be warranted [16]. Pulp capping is a procedure where calcium hydroxide with overlying sedative dressing is placed in the tooth to stimulate the formation of reparative dentin. The goal of a pulp cap is to arrest caries, preserve pulpal vitality and allow reparative dentin to be deposited [16]. For a successful pulp cap, the tooth should be free of symptoms and with a normal radiographic appearance indicating an absence of apical pathology. The assumption is that the deeper layers of dentin beneath the carious front is free or has a decreased number of bacteria. For this reason, the superficial layers of dentin are removed and a dressing agent is placed which allows for the deposition of reparative dentin. The procedure for an indirect pulp cap is done under rubber dam isolation. The initial carious excavation is done using hand pieces and the remaining carious area superficial to the pulp should be excavated using hand instruments leaving the last layer of carious dentin that if removed, would lead to a pulpal exposure. A dressing agent such as calcium hydroxide is placed over this thin dentinal layer and tooth is restored temporarily. Re-excavation of the tooth is done in approximately 6-8 weeks to evaluate the formation of reparative dentin in the area of the remaining carious front ${ }^{[16]}$. The disadvantage of an indirect pulp cap is the entry of bacteria into the pulp during the 
pulp capping procedure or after due to leakage of the coronal restoration [19]. This treatment option though has been advocated by Thompson and colleagues in their meta-analysis. This meta-analysis included an electronic data base search of which three randomized control studies met the inclusion criteria. One of which was a study by Mertz-Fairhurst et al using a randomized split mouth study designed to compare partial carious excavation in teeth sealed with composite to complete carious excavation in teeth restored with either sealed or unsealed amalgam. The study consisted of 123 patients aged 8-52. Patients were followed up at 6 months, 1 year, 2 years, 5 years and at 10 years. Teeth were examined both clinically to assess marginal integrity of restorations and recurrent decay as well as radiographically for presence of pathology. Study concluded that after 10 years with a $54 \%$ recall rate only $3.5 \%$ of teeth in the composite sealed cavity groups showed marginal deterioration. It was concluded that partial carious excavation in teeth sealed with composite arrested the carious lesion with an overall success rate of $70 \%{ }^{[20-23]}$.

In contrast to an indirect pulp cap, a direct pulp cap is recommended as the treatment of choice for a traumatic pulpal exposure when the size of the exposure is small and the time following trauma to treatment is short. Other studies have indicated that the prognosis of a direct pulp cap is higher when the pulpal exposure occurs as a result of mechanical reasons and not as a result of caries ${ }^{[20]}$. Carious exposure will result in bacterial invasion that will decrease the prognosis of a direct pulp cap [24]. Similar to an indirect pulp cap, the goal of a direct pulp cap is to promote healing and preservation of the pulp and promote reparative dentin deposition [19]. Success of a direct pulp cap is dependent on the ability to control bleeding at the site of pulpal exposure and the placement of a good sealing restoration after the procedure has been completed [19, 25]. 
Just as in performing an indirect pulp cap, a tooth needing a direct pulp cap should be isolated with a rubber dam [16]. Antimicrobial agents such as sodium hypochlorite or hydrogen peroxide or chlorhexidine have been advocated to clean the exposed area when soaked in a cotton pellet ${ }^{[16,26]}$. Calcium hydroxide or MTA is placed over the exposed area and a permanent restoration is placed to prevent coronal microleakage. Patients then present for subsequent follow up appointments to ensure continuous root development. If the size of the exposure is large then a pulpectomy or pulpotomy is advocated [16].

\section{Pulpotomy: Partial/ Full}

As opposed to a direct pulp cap, a partial pulpotomy can still be done even when the patient presents for treatment 7 days or more after the trauma occurred. The pulp in those instances is described as being hyperplastic and is confined only to the coronal pulp. Cvek in a clinical report on partial pulpotomies using calcium hydroxide in 60 permanent incisors in boys and girls aged 7 to 16 reported $96 \%$ success in treatment (try to end the sentence in numbers). The average time frame from trauma (complicated crown fracture) to treatment was three months with size of pulpal exposure varying between .05 to $4.0 \mathrm{~mm}$. These patients were followed for 31 months and success was defined as the absence of signs and symptoms, continuation of root development and absence of apical pathology [27]. In a meta analysis by Aguilar and colleagues an electronic and hand search of publicized articles comparing the success rates of direct pulp capping, partial and full pulpotomies were investigated [28]. Four randomized control trials, 5 cohort studies and 14 case series were included in the analysis. Success was assessed using both a clinical and radiographic evaluation. All teeth were grouped into follow up periods of greater than 6 months to a year, greater 
than a year to 2 years, greater than 2 years to 3 years and beyond three years. Direct pulp capping had a success rate ranging from $72.9 \%$ to $99.4 \%$. Success increased from $87.5 \%$ to $95.4 \%$ during the one to two year period but showed a decline after two years. When compared to the success of a partial pulpotomy, a direct pulp cap had a lower success rate after three years (72.9\% for direct pulp cap and $99.4 \%$ for partial pulpotomy).

A full pulpotomy is recommended when the apical portion of the pulp is healthy but the coronal pulp is highly inflamed [16]. These teeth should radiographically show an absence of apical pathology, minimal thermal sensitivity and an absence of percussion sensitivity. If gross decay is present, all decay is excavated again under rubber dam isolation. The coronal pulp is amputated using a bur and bleeding can be controlled using a moistened pellet soak in sodium hypochlorite [29]. Calcium hydroxide or MTA is placed over the remaining pulpal tissue and the tooth is permanently restored. If hemorrhage cannot be controlled then the clinician should use his or her judgment to assess the tooth and the need to perform a full pulpectomy as opposed to a full pulpotomy. In the meta analysis described previously by Aguilar et al 109 teeth were included in the radiographic and clinical analysis assessing the success of a full pulpotomy. Teeth were followed up from 1- 10 years. A success rate of 94\% was observed in teeth up to one year following treatment. This increased to $99.3 \%$ at the three year or more follow-up period. No significant differences were noted between calcium hydroxide and MTA when used as a dressing.The success of vital pulp therapy is highly dependent on case selection and the ability to carry out the most suitable treatment protocol. The possible explanation for a lower success rate observed with direct pulp caps can be attributed to the fact that presently there is no tool that can be used to 
assess the level of pulpal inflammation at an exposure site. Determining the degree of pulpal inflammation is subjective and based on the provider's assessment of what is too much bleeding. An error in that assessment can negatively impact success.

\section{b) Non-Vital Tooth Therapy}

The treatment alternatives for an immature permanent tooth with a necrotic pulp is either apexification or regenerative endodontics. Apexification has been the traditional treatment for immature teeth with necrotic pulps[30],[31],[32]. The aim of apexification is to induce the formation of a hard tissue barrier at the apex of the immature permanent tooth.

\section{Apexification}

Due to calcium hydroxide's success in pulp capping, calcium hydroxide has been the traditional material used in apexification. It has previously been shown to result in hard tissue formation when used as a pulp capping agent by creating an environment that is conducive to hard tissue deposition [33]. Calcium hydroxide has been shown to have a success rate ranging from 90\%-96\% [1, 27, 34]. Calcium hydroxide apexification involves multiple appointments. During the initial appointment, a working length of the tooth is obtained, the tooth is debrided biochemically and a calcium hydroxide dressing is placed. The patient returns in 4-6 weeks and the dressing is replaced. This replacement is continued every three months until an apical barrier can be detected clinically or radiographically $[35,36]$.Hard tissue formation can occur from 3 months to 24 months ${ }^{[36]}$. This variation in treatment time is not always consistent making it impossible to determine the number of months it will take for mineralized tissue to form or the number of intracanal medicament replacements necessary to produce success [37]. It has been stated that complete apical closure may not be necessary for completion of 
non-surgical root canal therapy so changes to the apex of an immature tooth that will allow successful obturation is what is required. A question of whether the calcium hydroxide dressing needs to be changed regularly has been investigated in a in vivo animal model in 40 premolars ${ }^{[38]}$. No significant differences were noted in teeth where calcium hydroxide paste was changed monthly compared to teeth where the dressing was replaced every three months. The quality of the apical barrier formed via the apexification process has also been assessed. Variations have been determined and have been categorized into 4 different clinical results ${ }^{[36]}$. One category is given to teeth which when viewed radiographically do not show evidence of apexification. These teeth, however, show signs of apical closure clinically when an instrument is inserted into the apical third. In the second and third groups a calcified bridge may be seen radiographically coronal to the apex of the tooth or pulp canal obliteration may be evident in the apical third of the root. In the fourth category the apex remains open with minimal changes in canal width [36]. In an in vitro study of twelve extracted teeth, a histological analysis of the apical third was done to determine the tissue type formed. It was concluded that the mineralized barrier formed contained tissue of cementum origin [39].

Although calcium hydroxide apexification has proven to be very successful, it has also been shown to have some disadvantages. Long term calcium hydroxide use can increase the likelihood of tooth fracture and can also result in possible reinfection of the tooth during the treatment period $[35,38,40-42]$. Fracture resistance can be decreased by approximately 50\% in one year according to an in vitro research study by Andreasen [40]. One of the theories that have been speculated is that calcium hydroxide has the ability to change the organic matrix in dentin by denaturing collagen therefore affecting its bond 
to hydroxyapatite crystals. This change in the dentin structure as a result of a high $\mathrm{pH}$ environment will impact the mechanical properties of dentin thus decreasing root strength and making the roots more vulnerable to fracture ${ }^{[40]} .885$ luxated necrotic incisors were analyzed radiographically for the incidence of inflammatory root resorption, cervical root fractures and ankylosis. The incidence of cervical root fracture was higher in immature permanent teeth (77\%) compared to mature teeth (approximately 25\%) and was dependent on the stage of root development [43]. Cervical root fracture was observed in 168 teeth. 61\% of these fractures occurred during calcium hydroxide treatment and the remaining fractures occurred after completion of nonsurgical root canal therapy. The etiology of most of the fractures was chewing or biting or a reoccurrence of injury.

Like calcium hydroxide, mineral trioxide aggregate (MTA) has been shown to result in a similar treatment success. MTA, as mentioned before is a tricalcium silicate cement which was introduced as a dental material in 1993 and was approved by the Food and Drug Administration in 1998 only to be used as an apical stop in apexification and for the repair of perforations due to iatrogenic errors or resorption during endodontic therapy. It has been used in various endodontic procedures and shows promising results due to its properties. Its properties can be attributed to its small particle size, alkaline $\mathrm{pH}$ and high compressive strength [44]. Holland theorized that the mechanism responsible for MTA induction of calcific tissue formation is caused by the reaction of tricalcium oxide and calcium forming calcium hydroxide [45]. An electronic and hand search was done to complete a comprehensive review of the properties and clinical applications of MTA ${ }^{[46]}$. MTA has great sealing ability, can set in the presence of moisture, is biocompatible and has antibacterial effects ${ }^{[47-49]}$. MTA can be used 
clinically to repair perforations and resorption defects, as a dressing in vital pulp therapy procedures such as indirect/direct pulp capping and pulpotomies[31,37]. In addition, it can also be used as a synthetic barrier for apexification and as a root end filling material during apicoectomies ${ }^{[46]}$. A few studies have compared calcium hydroxide apexification to MTA apexification. A preclinical study in dogs with immature teeth reported that MTA produced a more consistent barrier in the apical third when compared to that of calcium hydroxide. [31]. In a systematic review and meta-analysis by Chala and colleagues the efficacy of calcium hydroxide and MTA apexification was evaluated [50]. Using an electronic and hand search, only two prospective studies met the inclusion criteria which included information about the presence of apical barrier formation in immature teeth and resolution of signs and symptoms. These two studies which met the inclusion criteria provided a total of 50 teeth that could be used in the analysis [37, 51]. Results indicate that there is no significant difference between MTA and calcium hydroxide apexification. The authors did indicate that these two studies included a small number of teeth and therefore should not be utilized as strong evidence to support clinically based decisions. There have also been clinical studies evaluating MTA apexification alone. In a retrospective analysis of 144 teeth the authors compared one visit MTA apexification to two visit MTA apexification with an interappointment calcium hydroxide dressing. A 44\% recall rate was obtained within 5 years. A high success rate was achieved in both the single visit and two visit groups with no significant difference between the two $(93.5 \%$ in the one visit group and $90.5 \%$ in the two visit group) [32].

Despite the added benefits of MTA, the challenges associated with apexification procedures are that the dentinal walls remain thin and there is no increase in root 
length [52], [17]. As a result, these teeth have a high fracture risk not only during the apexification procedure but after the procedure has been completed [1],[17],[40],[53]. An alternative treatment option for immature teeth with pulpal necrosis is regenerative endodontics which aims to regenerate the pulp-dentin complex and thus allow the tooth to develop completely [17], [54],[55], [56],[57].

\section{Regenerative Endodontics}

Regenerative endodontics is a biologically based procedure designed to replace damaged tooth structures by regenerating the pulp-dentin complex ${ }^{[58]}$. It was first introduced in the 1970's by Dr. Nygaard Otsby and encompasses the principles of tissue engineering [59], [60]. Stem cells, growth factors and a scaffold are needed to regenerate the pulp dentin complex [61]. Stem cell sources include stem cells of the dental pulp, stem cells from human exfoliated deciduous teeth, periodontal ligament stem cells, dental follicle progenitor stem cells, stem cells from the apical papilla and bone marrow stem cells [53, 62]. In addition to stem cells, a scaffold is needed to provide structural support, enable cell attachment while providing an environment that is conducive for regeneration [53, 63]. Some examples of scaffolds include MTA, hydrogels, collagen and

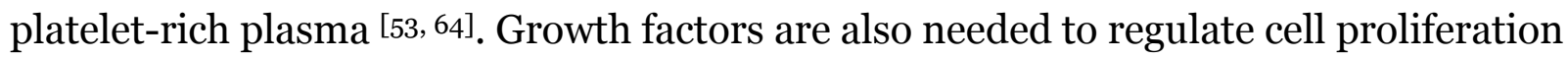
and differentiation. Regenerative potential has been associated with a subset of transforming growth factor family, bone morphogenic proteins [65]. In addition, other growth factors with pulp-dentin regenerative abilities include fibroblast growth factor, platelet derived growth factor and vascular endothelial growth factors. [66]

The most commonly used method of regeneration termed revascularization was introduced in a case report by Iwaya and later in 2004 by Banchs and Trope [54, 67]. This was presented as an alternative treatment for an immature permanent tooth with a 
necrotic pulp and an apical diameter of $1.1 \mathrm{~mm}$. This diameter was confirmed during an investigation of the rate of revascularization of reimplanted teeth using an in vivo animal model [68]. Revascularization did not occur in teeth with an apical diameter of $1 \mathrm{~mm}$ or less therefore a minimum of $1.1 \mathrm{~mm}$ diameter was recommended for pulpal regeneration. The revascularization protocol involves two major steps. The initial step is canal disinfection and the final step is the creation of a blood clot below the cementoenamel junction. This blood clot is then sealed using both MTA and a permanent restoration [54]. There has been some debate over the term revascularization verses regeneration but with the institution of tissue engineering principles, the term regenerative endodontics is most appropriate.

There has also been a tremendous level of excitement and a growing body of evidence which is suggestive of the success of this procedure. The American Association of Endodontists (AAE) recognizes regenerative endodontics as being within the scope of endodontics and has provided clinical considerations for this treatment alternative. All post graduate programs are now mandated by the $\mathrm{AAE}$ to teach regenerative endodontics. This mandate emphasizes the promising potential of regenerative endodontics and the need to teach it both clinically and didactically. Moreover, the AAE in an effort to increase research in the field of regeneration has provided research grants and ask that we as providers upload our cases into an online data base that is supervised by Dr. Alan Law.

Case studies and case reports have shown that regenerative endodontic procedures can successfully heal apical periodontitis and result in an increase in dentin thickness and continued root development [54], [56], [57]. Most published reports on regenerative endodontic therapy focus on treatment factors such as canal disinfection 
and radiographic changes or patient factors such as clinical symptoms and how each factor can impact treatment outcome.

As a result, different materials have been used to disinfect the canal system such as intracanal medicaments and irrigants. Triple antibiotic paste (TAP), a mixture of ciprofloxacin, metronidazole and minocycline has been shown to be very efficacious against endodontic bacteria present in the necrotic root canal system [56, 69-71]. TAP paste has also been shown to result in successful regenerative treatment of immature permanent teeth even resulting in a positive response to the electric pulp test at subsequent follow up appointments [72]. One of the disadvantages of using TAP is staining which is caused by the presence of minocycline ${ }^{[73]}$. Some case reports have shown that with the use of a double antibiotic paste which lacks minocycline regeneration can be as successful as with the use of a TAP [67]. Calcium hydroxide, another intracanal medicament which was once thought to be detrimental to the survival of stem cells has been shown to also be effective in canal disinfection leading to a successful outcome in regenerative endodontics [74].

Due to the large size of the pulp chamber, the concern with using endodontic irrigants is not the ability to introduce the irrigant into the canal but the ability to prevent the irrigant from irritating the periapical tissues thus damaging the stem cells present in the apical papilla. There is also the concern that canal instrumentation may weaken the tooth tremendously due to thin dentinal walls. High concentrations of sodium hypochlorite which have been shown to be effective in mature teeth may be detrimental to stem cell survival in an immature tooth [75]. Therefore these concentrations may need to be reduced to enhance regeneration. Chlorhexidine, another endodontic irrigant has been shown to be highly toxic to regenerative cells and should 
not be used. For successful regeneration to occur the clinician needs to consider stem cell viability and growth factor dissolution from dentin reservoirs. Ethylene-diamine tetracetic acid has been shown to enhance stem cell survival and would be preferred as an irrigant of choice for regenerative procedures [76].

Since the reintroduction of regenerative endodontics, a specific protocol has not been implicated and there has been a call for increased research in this specific area as well as establishing guidelines for case selection. Two of the many questions raised was how does one quantitatively prove that there has certainly been an increase in root length and dentin thickness and is the resolution of signs and symptoms termed success even though root development remained the same. Bose et al used a computer software Image $\mathrm{J}$ to correct errors in preoperative and post-operative periapical images. This allowed one to determine any differences in root length and dentin thickness [52]. A standardized protocol to determine the radiographic root area (RRA) was formulated and validated based on some of the principles used by Bose et al [77]. Similarly, the RRA is analyzed using image $\mathrm{J}$ which takes into account the root area bordered by the mesial and distal dimensions of the tooth at the CEJ level and that of the periodontal ligament space. To account for the area of the pulp space the entire space is outlined by the software and the area is determined. This area includes the entire surface that is observed in a two dimensional radiograph. It has been shown to be clinically useful and an effective measure to evaluate radiographic changes at subsequent follow up appointments. In spite of the success associated with regenerative endodontics, there is still a great deal of skepticism surrounding its use as a treatment option due to lack of sufficient evidence. 
Another question that has been raised is whether or not the pulp-dentin complex is regenerated and if it is not then is complete regeneration important for treatment success. In vivo animal studies and in vitro studies with a histological analysis of tissue samples from the regenerated pulp have shown that the material regenerated is of an osteoid and cementoid origin which may or may not have dentinal tissue. This newly formed material lacks the cells (odontoblasts, fibroblasts) which are present in the pulpdentin complex $[78,79]$. Other animal studies have shown deposition of dentin like materials with the use of stem cell regeneration [80]. There exist a dilemma between clinical success and histological outcomes. In cases where a patient is asymptomatic and apical pathology is not present histological analysis of pulpal and apical tissue has shown that there is some degree of inflammation still present. Would it be reasonable to say that a particular tooth has healed when referring to signs and symptoms despite the histological analysis? A similar mode of thinking may be needed for regenerative endodontics where resolution of symptoms, apical pathology and sinus tract in addition to no symptoms may still be regarded as successful despite the findings of the histological analysis of the tissue type being regenerated [81]. For example, in a small pilot study, 14 teeth were treated with the revascularization protocol. $93 \%$ of these teeth showed resolution of apical pathology and patients were no longer symptomatic. Despite the radiographic and clinical improvements, thickening of the dentinal walls occurred in $57 \%$ of cases and increased root length was noted in $71 \%$ of cases [57].

Performing the revascularization protocol can also be technique sensitive. Some recommendations have been made to improve success by using a collagen plug to allow for more precise MTA placement, using an anesthetic without epinephrine to induce bleeding and determining patient/parent compliance ${ }^{[82]}$. Regenerative procedures can 
take multiple visits therefore it is important to determine if the patient will present for additional follow-ups and recalls. Patients and their parents should be made aware that tooth may stain either due to the presence of minocycline in TAP or MTA [82].

\section{Apexification vs Regeneration}

There have been a few studies comparing the success rate of apexification versus regeneration. MTA apexification, calcium hydroxide apexification and regeneration were compared in an in vivo human study. Results were based on tooth survivability, resolution of signs and symptoms and in addition the percent increase in root length and width ${ }^{[17]}$. Percent increase in root length and width were greatest in the revascularization group. Tooth survival was highest in the MTA apexification and revascularization groups as opposed to findings in the calcium hydroxide apexification group. Another study compared the results of regeneration with calcium hydroxide verses TAP to that observed with MTA apexification ${ }^{[52]}$. An increase in root length and thickness was observed with no significant differences in the calcium hydroxide and TAP groups using a computerized program Image J with TubroReg plug-in. The teeth in the apexification group showed the least change in root development. Despite the success with apexification and regenerative procedures these endodontic procedures for the most part have not been able to reliably achieve ideal success in traumatized teeth with periapical pathology [53]. Ideal success would include the resolution of radiographic pathology, absence of clinical signs and symptoms and the re-establishment of the pulpal immune response. More research is needed in order to develop a protocol that can consistently produce ideal success. 


\section{Published Surveys on Regenerative Endodontics}

To our knowledge, no study has sought to compare provider (endodontists and pediatric dentists) factors which influence the decision to choose regenerative endodontic therapy versus apexification procedures. Only a limited number of studies have queried endodontists about this treatment procedure. These include a survey of the diplomats of the American Board of Endodontists and other dental practitioners about their perception of regenerative endodontic procedures [83]. The survey had a $56 \%$ response rate $(\mathrm{N}=100)$ of which $96 \%$ of the responders thought that regenerative endodontics should be incorporated into endodontic treatment. Close to $90 \%$ of the participants were interested in stem cell banking by salvaging teeth and other viable dental tissues. Although half of the responders were using various forms of regenerative procedures in their practices such as membranes and scaffolds, about 50\% of them were still not convinced of the success of regenerative endodontic procedures. This study, however, did not ask specific questions about possible barriers or reasons for having doubts about the lack of treatment success.

A more recent survey queried dental residents $(\mathrm{N}=34)$ about their expectations towards regenerative endodontics [84]. This survey focused on their clinical judgment, ethical beliefs and current practices. $85 \%$ of those surveyed had not received any form of training or continuing education in the field of regenerative endodontics. Very similar to the previously described survey, about $55 \%$ of dentists questioned the success of regenerative endodontics. Although the majority of dentists are enthusiastic about this treatment option, there is a constant call for further research and evidence for regenerative endodontics. 
A similar study was done in India where the opinions of endodontic residents were surveyed to determine their overall impression of regenerative endodontics $(\mathrm{N}=200)^{[85]}$. In contrast to the previous survey, residents were asked questions on the treatment of a necrotic immature tooth, stem cell use and their individual opinions of the clinical implications of regenerative endodontics. There was a $75 \%$ response rate but some participants failed to answer a particular question or chose multiple answers for a single question. About 50\% of the respondents indicated that they had received some form of training in the area of regenerative endodontics. Close to $90 \%$ agreed that regenerative procedures should be included as a treatment option in dentistry. The majority of the participants agreed that stem cell banking could be used to regenerate dental tissues. The greatest barrier selected by $75 \%$ of participants was the cost of treatment. This study was geared mainly to collect information on the opinions of endodontic residents in the field of regenerative endodontics but did not compare treatment options for the necrotic tooth and why one treatment option would be preferred to another.

As discussed, current research on regenerative endodontics is focused on the development of new scaffolds and treatment protocols. What is missing is an understanding of the factors which influence the decision to choose between regenerative endodontic treatment and apexification. The scientific literature lacks any evidence on barriers to regenerative endodontics. It is important to understand the provider factors that can hinder patient acceptance of regenerative procedures in an effort to encourage patient acceptance. Despite ongoing research in this field and the successful outcomes that have been published about $50 \%$ of dentists including endodontist are still not convinced that treatment can be successful. This leads to the 
question of why are they not convinced; A question that has not been answered in the scientific literature.

This study will seek to answer this question by determining the barriers that pediatric dentists and endodontists face that influence their perception of treatment success and their unwillingness to present it as a possible treatment option. In order to identify provider factors we propose to survey pediatric dentists and endodontists who perform treatments on immature permanent teeth. 


\section{REFERENCES}

1. Witherspoon, D.E. and K. Ham, One-visit apexification: technique for inducing root-end barrier formation in apical closures. Pract Proced Aesthet Dent, 2001. 13(6): p. 455-60; quiz 462.

2. $\quad$ Arens, D.E., Treatment of the incompletely formed tooth. Ill Dent J, 1978. 47(3): p. 110-6.

3. Op Heij, D.G., et al., Age as compromising factor for implant insertion. Periodontol 2000, 2003. 33: p. 172-84.

4. Moorrees, C.F., E.A. Fanning, and E.E. Hunt, Jr., Age Variation of Formation Stages for Ten Permanent Teeth. J Dent Res, 1963. 42: p. 1490-502.

5. $\quad$ Mason, C., et al., A retrospective study of unerupted maxillary incisors associated with supernumerary teeth. Br J Oral Maxillofac Surg, 2000. 38(1): p. $62-5$.

6. Andreasen, J.O., Etiology and pathogenesis of traumatic dental injuries. A clinical study of 1,298 cases. Scand J Dent Res, 1970. 78(4): p. 329-42.

7. Hecova, H., et al., A retrospective study of 889 injured permanent teeth. Dent Traumatol, 2010. 26(6): p. 466-75.

8. Andreasen, J.O. and J.J. Ravn, Epidemiology of traumatic dental injuries to primary and permanent teeth in a Danish population sample. Int J Oral Surg, 1972. 1(5): p. 235-9.

9. Borum, M.K. and J.O. Andreasen, Therapeutic and economic implications of traumatic dental injuries in Denmark: an estimate based on 7549 patients treated at a major trauma centre. Int J Paediatr Dent, 2001. 11(4): p. 249-58.

10. Andreasen, J.O., et al., Replantation of 400 avulsed permanent incisors. 4. Factors related to periodontal ligament healing. Endod Dent Traumatol, 1995. 11(2): p. 76-89.

11. Nikoui, M., D.J. Kenny, and E.J. Barrett, Clinical outcomes for permanent incisor luxations in a pediatric population. III. Lateral luxations. Dent Traumatol, 2003. 19(5): p. 280-5.

12. Izumi, T., et al., Immunohistochemical study on the immunocompetent cells of the pulp in human non-carious and carious teeth. Arch Oral Biol, 1995. 40(7): p. 609-14. 
13. Brannstrom, M. and P.O. Lind, Pulpal response to early dental caries. J Dent Res, 1965. 44(5): p. 1045-50.

14. Reeves, R. and H.R. Stanley, The relationship of bacterial penetration and pulpal pathosis in carious teeth. Oral Surg Oral Med Oral Pathol, 1966. 22(1): p. 59-65.

15. Bergenholtz, G., Inflammatory response of the dental pulp to bacterial irritation. J Endod, 1981. 7(3): p. 100-4.

16. Gutmann, J.L. and J.F. Heaton, Management of the open (immature) apex. 1. Vital teeth. Int Endod J, 1981. 14(3): p. 166-72.

17. Jeeruphan, T., et al., Mahidol study 1: comparison of radiographic and survival outcomes of immature teeth treated with either regenerative endodontic or apexification methods: a retrospective study. J Endod, 2012. 38(10): p. 1330-6.

18. Webber, R.T., Apexogenesis versus apexification. Dent Clin North Am, 1984. 28(4): p. 669-97.

19. Hilton, T.J., Keys to clinical success with pulp capping: a review of the literature. Oper Dent, 2009. 34(5): p. 615-25.

20. Thompson, V., et al., Treatment of deep carious lesions by complete excavation or partial removal: a critical review. J Am Dent Assoc, 2008. 139(6): p. 705-12.

21. Mertz-Fairhurst, E.J., G.S. Schuster, and C.W. Fairhurst, Arresting caries by sealants: results of a clinical study. J Am Dent Assoc, 1986. 112(2): p. 194-7.

22. Mertz-Fairhurst, E.J., et al., Clinical performance of sealed composite restorations placed over caries compared with sealed and unsealed amalgam restorations. J Am Dent Assoc, 1987. 115(5): p. 689-94.

23. Mertz-Fairhurst, E.J., et al., Ultraconservative and cariostatic sealed restorations: results at year 10. J Am Dent Assoc, 1998. 129(1): p. 55-66.

24. Watts, A. and R.C. Paterson, Bacterial contamination as a factor influencing the toxicity of materials to the exposed dental pulp. Oral Surg Oral Med Oral Pathol, 1987. 64(4): p. 466-74.

25. Baume, L.J. and J. Holz, Long term clinical assessment of direct pulp capping . Int Dent J, 1981. 31(4): p. 251-60.

26. Costa, C.A., C.A. Edwards, and C.T. Hanks, Cytotoxic effects of cleansing solutions recommended for chemical lavage of pulp exposures. Am J Dent, 2001. 14(1): p. 25-30. 
27. Cvek, M., A clinical report on partial pulpotomy and capping with calcium hydroxide in permanent incisors with complicated crown fracture. J Endod, 1978. 4(8): p. 232-7.

28. Aguilar, P. and P. Linsuwanont, Vital pulp therapy in vital permanent teeth with cariously exposed pulp: a systematic review. J Endod, 2011. 37(5): p. 581-7.

29. Vargas, K.G., B. Packham, and D. Lowman, Preliminary evaluation of sodium hypochlorite for pulpotomies in primary molars. Pediatr Dent, 2006. 28(6): p. $511-7$.

30. Rafter, M., Apexification: a review. Dent Traumatol, 2005. 21(1): p. 1-8.

31. Shabahang, S., et al., A comparative study of root-end induction using osteogenic protein-1, calcium hydroxide, and mineral trioxide aggregate in dogs. J Endod, 1999. 25(1): p. 1-5.

32. Witherspoon, D.E., et al., Retrospective analysis of open apex teeth obturated with mineral trioxide aggregate. J Endod, 2008. 34(10): p. 1171-6.

33. Attalla, M.N. and A.A. Noujaim, Role of calcium hydroxide in the formation of reparative dentine. J Can Dent Assoc (Tor), 1969. 35(5): p. 267-9.

34. Cvek, M., Treatment of non-vital permanent incisors with calcium hydroxide. I. Follow-up of periapical repair and apical closure of immature roots. Odontol Revy, 1972. 23(1): p. 27-44.

35. Abbott, P.V., Apexification with calcium hydroxide--when should the dressing be changed? The case for regular dressing changes. Aust Endod J, 1998. 24(1): p. 27-32.

36. Frank, A.L., Therapy for the divergent pulpless tooth by continued apical formation. J Am Dent Assoc, 1966. 72(1): p. 87-93.

37. El-Meligy, O.A. and D.R. Avery, Comparison of apexification with mineral trioxide aggregate and calcium hydroxide. Pediatr Dent, 2006. 28(3): p. 24853 .

38. Felippe, M.C., et al., The effect of the renewal of calcium hydroxide paste on the apexification and periapical healing of teeth with incomplete root formation. Int Endod J, 2005. 38(7): p. 436-42.

39. Cvek, M. and B. Sundstrom, Treatment of non-vital permanent incisors with calcium hydroxide. $V$. Histologic appearance of roentgenographically demonstrable apical closure of immature roots. Odontol Revy, 1974. 25(4): $\mathrm{p}$. 379-91. 
40. Andreasen, J.O., B. Farik, and E.C. Munksgaard, Long-term calcium hydroxide as a root canal dressing may increase risk of root fracture. Dent Traumatol, 2002. 18(3): p. 134-7.

41. Grigoratos, D., et al., Effect of exposing dentine to sodium hypochlorite and calcium hydroxide on its flexural strength and elastic modulus. Int Endod J, 2001. 34(2): p. 113-9.

42. Sheehy, E.C. and G.J. Roberts, Use of calcium hydroxide for apical barrier formation and healing in non-vital immature permanent teeth: a review. $\mathrm{Br}$ Dent J, 1997. 183(7): p. 241-6.

43. Cvek, M., Prognosis of luxated non-vital maxillary incisors treated with calcium hydroxide and filled with gutta-percha. A retrospective clinical study. Endod Dent Traumatol, 1992. 8(2): p. 45-55.

44. Torabinejad, M., et al., Physical and chemical properties of a new root-end filling material. J Endod, 1995. 21(7): p. 349-53.

45. Holland, R. and V. de Souza, Ability of a new calcium hydroxide root canal filling material to induce hard tissue formation. J Endod, 1985. 11(12): p. 53543 .

46. Parirokh, M. and M. Torabinejad, Mineral trioxide aggregate: a comprehensive literature review--Part III: Clinical applications, drawbacks, and mechanism of action. J Endod, 2010. 36(3): p. 400-13.

47. Torabinejad, M., et al., Dye leakage of four root end filling materials: effects of blood contamination. J Endod, 1994. 20(4): p. 159-63.

48. Torabinejad, M., et al., Cytotoxicity of four root end filling materials. J Endod, 1995. 21(10): p. 489-92.

49. Torabinejad, M., et al., Comparative investigation of marginal adaptation of mineral trioxide aggregate and other commonly used root-end filling materials. J Endod, 1995. 21(6): p. 295-9.

50. Chala, S., R. Abouqal, and S. Rida, Apexification of immature teeth with calcium hydroxide or mineral trioxide aggregate: systematic review and meta-analysis. Oral Surg Oral Med Oral Pathol Oral Radiol Endod, 2011. 112(4): p. e36-42.

51. Pradhan, D.P., et al., Comparative evaluation of endodontic management of teeth with unformed apices with mineral trioxide aggregate and calcium hydroxide. J Dent Child (Chic), 2006. 73(2): p. 79-85.

52. Bose, R., P. Nummikoski, and K. Hargreaves, A retrospective evaluation of radiographic outcomes in immature teeth with necrotic root canal systems 
treated with regenerative endodontic procedures. J Endod, 2009. 35(10): p. 1343-9.

53. Hargreaves, K.M., A. Diogenes, and F.B. Teixeira, Treatment options: biological basis of regenerative endodontic procedures. Pediatr Dent, 2013. 35(2): p. 12940 .

54. Banchs, F. and M. Trope, Revascularization of immature permanent teeth with apical periodontitis: new treatment protocol? J Endod, 2004. 30(4): p. 196200.

55. Chueh, L.H. and G.T. Huang, Immature teeth with periradicular periodontitis or abscess undergoing apexogenesis: a paradigm shift. J Endod, 2006. 32(12): p. 1205-13.

56. Jung, I.Y., S.J. Lee, and K.M. Hargreaves, Biologically based treatment of immature permanent teeth with pulpal necrosis: a case series. Tex Dent J, 2012. 129(6): p. 601-16.

57. Shah, N., et al., Efficacy of revascularization to induce apexification/apexogensis in infected, nonvital, immature teeth: a pilot clinical study. J Endod, 2008. 34(8): p. 919-25; Discussion 1157.

58. Murray, P.E., F. Garcia-Godoy, and K.M. Hargreaves, Regenerative endodontics: a review of current status and a call for action. J Endod, 2007. 33(4): p. 377-90.

59. Ostby, B.N., The role of the blood clot in endodontic therapy. An experimental histologic study. Acta Odontol Scand, 1961. 19: p. 324-53.

60. Nygaard-Ostby, B. and O. Hjortdal, Tissue formation in the root canal following pulp removal. Scand J Dent Res, 1971. 79(5): p. 333-49.

61. Hargreaves, K.M., et al., Regeneration potential of the young permanent tooth: what does the future hold? J Endod, 2008. 34(7 Suppl): p. S51-6.

62. Nosrat, A., A. Seifi, and S. Asgary, Regenerative endodontic treatment (revascularization) for necrotic immature permanent molars: a review and report of two cases with a new biomaterial. J Endod, 2011. 37(4): p. 562-7.

63. Mao, J.J., et al., Regenerative endodontics: barriers and strategies for clinical translation. Dent Clin North Am, 2012. 56(3): p. 639-49.

64. Torabinejad, M. and H. Faras, A clinical and histological report of a tooth with an open apex treated with regenerative endodontics using platelet-rich plasma. J Endod, 2012. 38(6): p. 864-8. 
65. Ham, K.A., et al., Preliminary evaluation of BMP-2 expression and histological characteristics during apexification with calcium hydroxide and mineral trioxide aggregate. J Endod, 2005. 31(4): p. 275-9.

66. Kim, S.G., et al., Effects of growth factors on dental stem/progenitor cells. Dent Clin North Am, 2012. 56(3): p. 563-75.

67. Iwaya, S.I., M. Ikawa, and M. Kubota, Revascularization of an immature permanent tooth with apical periodontitis and sinus tract. Dent Traumatol, 2001. 17(4): p. 185-7.

68. Kling, M., M. Cvek, and I. Mejare, Rate and predictability of pulp revascularization in therapeutically reimplanted permanent incisors. Endod Dent Traumatol, 1986. 2(3): p. 83-9.

69. Hoshino, E., et al., In-vitro antibacterial susceptibility of bacteria taken from infected root dentine to a mixture of ciprofloxacin, metronidazole and minocycline. Int Endod J, 1996. 29(2): p. 125-30.

70. Sato, I., et al., Sterilization of infected root-canal dentine by topical application of a mixture of ciprofloxacin, metronidazole and minocycline in situ. Int Endod J, 1996. 29(2): p. 118-24.

71. Windley, W., 3rd, et al., Disinfection of immature teeth with a triple antibiotic paste. J Endod, 2005. 31(6): p. 439-43.

72. $\quad$ Ding, R.Y., et al., Pulp revascularization of immature teeth with apical periodontitis: a clinical study. J Endod, 2009. 35(5): p. 745-9.

73. Kim, J.H., et al., Tooth discoloration of immature permanent incisor associated with triple antibiotic therapy: a case report. J Endod, 2010. 36(6): p. 1086-91.

74. Cehreli, Z.C., et al., Regenerative endodontic treatment (revascularization) of immature necrotic molars medicated with calcium hydroxide: a case series. J Endod, 2011. 37(9): p. 1327-30.

75. $\quad$ Ring, K.C., et al., The comparison of the effect of endodontic irrigation on cell adherence to root canal dentin. J Endod, 2008. 34(12): p. 1474-9.

76. Galler, K.M., et al., Dentin conditioning codetermines cell fate in regenerative endodontics. J Endod, 2011. 37(11): p. 1536-41.

77. Flake, N.M., et al., A standardized novel method to measure radiographic root changes after endodontic therapy in immature teeth. J Endod, 2014. 40(1): p. 46-50. 
78. Dylewski, J.J., Apical closure of nonvital teeth. Oral Surg Oral Med Oral Pathol, 1971. 32(1): p. 82-9.

79. Ghose, L.J., V.S. Baghdady, and Y.M. Hikmat, Apexification of immature apices of pulpless permanent anterior teeth with calcium hydroxide. J Endod, 1987. 13(6): p. 285-90.

8o. Huang, G.T., et al., Stem/progenitor cell-mediated de novo regeneration of dental pulp with newly deposited continuous layer of dentin in an in vivo model. Tissue Eng Part A, 2010. 16(2): p. 605-15.

81. Green, T.L., et al., Radiographic and histologic periapical findings of root canal treated teeth in cadaver. Oral Surg Oral Med Oral Pathol Oral Radiol Endod, 1997. 83(6): p. 707-11.

82. Petrino, J.A., et al., Challenges in regenerative endodontics: a case series. $\mathrm{J}$ Endod, 2010. 36(3): p. 536-41.

83. Epelman, I., et al., A practitioner survey of opinions toward regenerative endodontics. J Endod, 2009. 35(9): p. 1204-10.

84. Manguno, C., et al., A survey of dental residents' expectations for regenerative endodontics. J Endod, 2012. 38(2): p. 137-43.

85. Utneja, S., et al., A survey of attitude and opinions of endodontic residents towards regenerative endodontics. J Conserv Dent, 2013. 16(4): p. 314-8.

86. Kelley, K., et al., Good practice in the conduct and reporting of survey research. Int J Qual Health Care, 2003. 15(3): p. 261-6. 
Manuscript

\section{Section П}

\section{"Provider Perceptions of Treatment Options for Immature Permanent Teeth"}

\section{Introduction}

An immature permanent tooth is a tooth with incomplete root formation which can hinder the ability to obturate the canal space using conventional root canal therapy techniques ${ }^{[1]}$ The primary aim of endodontic treatment is the completion of chemomechanical instrumentation which reduces the microbial concentration and therefore allows the clinician to complete canal obturation. A large apical diameter in addition to short roots are some of the factors that limit the survival rate following endodontic treatment of an immature permanent tooth. Due to variations in apical size and dentinal wall thickness, an insult to an immature permanent tooth such as trauma or caries while it is still developing can halt root development thus decreasing the prognosis and tooth survival. Despite these limitations, immature permanent teeth whether diagnosed with irreversible pulpitis or pulpal necrosis have been successfully treated using different treatment options.

Treatment options vary depending on the pulpal diagnosis. The traditional method of treating a vital pulp with apexogenesis has been shown to be very successful for the treatment of immature permanent teeth diagnosed with irreversible pulpitis ${ }^{[1]}$. Pulp capping whether direct or indirect and pulpotomies are some of the procedures that help preserve pulp vitality ${ }^{[16]}$. In the event that vital pulp therapy becomes unsuccessful, alternative methods of treatment are available and are similar to that used 
for a tooth diagnosed with pulpal necrosis. Present treatment options for a tooth diagnosed with pulpal necrosis are apexification and regenerative endodontics.

Historically, non-vital teeth were treated with apexification prior to the completion of non-surgical root canal therapy ${ }^{[1]}$. The aim of apexification is to induce the formation of a hard tissue barrier at the apex of a necrotic immature permanent tooth. Due to calcium hydroxide's success in pulp capping, it has been the traditional material used in apexification. It has previously been shown to result in hard tissue formation when used as a pulp capping agent by creating an environment that is conducive to hard tissue deposition [33]. Calcium hydroxide apexification has a high success rate ranging from $90 \%-96 \%[1,27,34]$. but it has also been shown to have some disadvantages. Long term calcium hydroxide use increases the likelihood of tooth fracture. The multiple appointments and long treatment period may result in possible reinfection of the root canal system [35, 38, 40-42]. Mineral trioxide aggregate (MTA) apexification was introduced as an alternative to calcium hydroxide apexification and has similar or higher success rates [50]. Despite the success of both MTA and calcium hydroxide apexification, there are limitations. The challenges associated with apexification procedures are that the dentinal walls remain thin and there is no increase in root length $[17,52]$. As a result, these teeth have a high fracture risk not only during the apexification procedure but also after the procedure has been completed $[1,17,40,53,61]$. To address these challenges, a new treatment alternative termed regenerative endodontics was re-introduced.

Regenerative endodontics is a biologically based procedure designed to replace damaged tooth structures by regenerating the pulp-dentin complex [58]. It was first introduced in the 1970's by Dr. Nygaard Otsby and encompasses the principles of tissue 
engineering [59,60]. Stem cells, growth factors and a scaffold are needed to regenerate the pulp dentin complex ${ }^{[61]}$. With new scientifically proven modified advanced materials and techniques, immature permanent teeth with non-vital pulps can now be

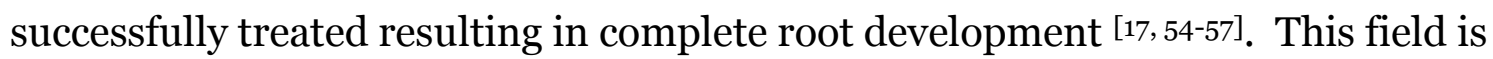
growing exponentially leading to its acceptance by the American Association of Endodontists (AAE).

The AAE has accepted regenerative endodontics as being within the scope of endodontics and has provided clinical considerations for this treatment alternative. A statement was released stating that effective January $1^{\text {st }} 2014$ all post graduate programs in the field of endodontics were mandated to teach regenerative endodontics and to allow their residents to perform regenerative endodontic procedures as part of their curriculum prior to their graduation. The AAE by releasing this statement emphasizes the promising potential of regenerative endodontics and the need to teach it both clinically and didactically. As a result this change has led to modifications to the accreditation standards for all endodontic residency programs and increased funding in regenerative endodontic research. Despite the increase in regenerative endodontic studies being published yearly, most of the studies published are case reports or case series, studies evaluating stem cells, scaffolds or growth factors, studies on trauma and a few in vitro histological analyses of extracted teeth. There are a lack of published studies evaluating the use of this treatment by endodontists and what their perceptions are regarding this treatment option.

To our knowledge, no study has sought to investigate factors that influence the decision of endodontists to choose regenerative endodontic therapy versus apexification procedures. Only a limited number of studies have queried endodontists about this 
treatment procedure. These include a survey of the diplomats of the American Board of Endodontists and other dental practitioners about their perception of regenerative endodontic procedures ${ }^{[83]}$. The survey had a $56 \%$ response rate $(\mathrm{N}=100)$ of which $96 \%$ of the responders thought that regenerative endodontics should be incorporated into endodontic treatment. Close to $90 \%$ of the participants were interested in stem cell banking by salvaging teeth and other viable dental tissues. Although half of the responders were using various forms of regenerative procedures in their practices such as membranes and scaffolds, about $50 \%$ of them were still not convinced of the success of regenerative endodontic procedures. This study, however, did not ask specific questions about possible barriers or reasons for having doubts about the lack of treatment success.

A more recent survey queried dental residents $(\mathrm{N}=34)$ about their expectations towards regenerative endodontics [84]. This survey focused on their clinical judgment, ethical beliefs and current practices. $85 \%$ of those surveyed had not received any form of training or continuing education in the field of regenerative endodontics. Very similar to the previously described survey, about $55 \%$ of dentists questioned the success of regenerative endodontics. Although the majority of dentists are enthusiastic about this treatment option, there is a constant call for further research and evidence for regenerative endodontics.

The purpose of this study was to assess the utilization and preference of endodontic treatment of an immature permanent tooth diagnosed with pulpal necrosis by surveying endodontists in four geographical states. Our hypothesis was that the utilization of regenerative endodontics by endodontists and the preferable choice of 
treatment based on specific considerations is the same for endodontists in all four geographical states.

\section{Materials and Method}

This study was approved by the UNC Biomedical Institutional Review Board of the Office of Human Research Ethics. We identified and recruited endodontists licensed to practice in the states of North Carolina (NC), New York (NY), California (CA) and Texas (TX) by using the lists of registered providers in each state. We designed the survey to investigate different areas of interest: the frequency of pulpal necrosis seen in young immature permanent teeth, the factors influencing the decision to choose regenerative endodontics or apexification as well as the experience and knowledge of the clinician.

We created the surveys both electronically using Qualtrics software (Qualtrics, Provo, UT) and in paper format using Teleform (Cardiff Software, Vista, CA). The latter was used for providers who did not respond to the electronic version of the survey or for those whose email addresses were not listed on the states registry. All responses obtained in the qualtrics program were anonymized to maintain provider confidentiality. Similar to the electronic surveys, the paper responses were coded to a separate linkage file to protect the privacy of the providers.

Prior to distribution of the electronic and paper formats of the survey, we pilot tested the survey with a group of residents and faculty to ensure that the questions were clear and concise and to assure that there were no problems with the survey links. We distributed the electronic versions of the endodontic survey using the Salant and Dillman method with three contacts per respondent ${ }^{[86]}$. We sent an email to each endodontist containing a cover letter and an individual survey link. If no response was 
obtained after two weeks, a reminder email was sent to all non-responders who were identified by Qualtrics. Two weeks after this initial reminder, a final reminder was again sent to all non-responders and the survey was kept active for an extra four weeks. After the extended four weeks, we closed the electronic version of the survey. All responses from the electronic survey were recorded in the Qualtrics program to maintain security and patient confidentiality. All non-responders were mailed a paper format of the survey. Each mailed envelope contained a cover letter and a copy of the survey. Responses were collected for an additional four weeks at the end of which data collection was concluded.

We inspected the paper format of the surveys visually to ensure proper survey completion prior to having them scanned and recorded electronically to reduce entry errors. Providers were excluded from data analysis if they did not perform endodontic procedures on children, if they were retired, or not actively practicing endodontics. We combined all the electronic and teleform responses into a master data set which allowed for statistical analysis.

Descriptive statistics was used to assess proportions and percentages of the items in the survey. Data was analyzed using predictive analytic software version 20 (SPSS Inc, Chicago, IL). The primary outcome of interest for those who provided endodontic care to children and adolescents was the procedure used (apexification vs regeneration vs both vs neither). Potential explanatory variables include specialty, state, frequency with which children with pulpal necrosis were seen, education during residency, continuing education (CE) courses in apexification and regenerative endodontics, graduation year, race, and practice type. Bivariate analysis was performed using ChiSquare. Multinominal regression was also used to model the effect of multiple 
explanatory variables on the outcome. Secondary outcomes of interest were the "preferable" choice of treatment for the 8 considerations in the choice of treatment. Bivariate and logistic regression was used to explore the effect of the explanatory variables on the preferable choice. Level of significance was set at 0.05 .

\section{Results}

The electronic and/or paper formats of the survey was distributed to 1615 endodontists in the states of NY, CA, TX and NC. Table 1 displays the number of endodontists who were surveyed in each state. The total number of emails sent, the number of emails undelivered and the number of electronic surveys taken in each state are recorded in Figure 1.

\section{Demographics}

Respondent demographics are reported in table 2. A total of 532 endodontists responded to the survey; 306 electronically and 226 from the paper format of the survey (32.9\% response rate). Sixty nine endodontists indicated that they do not perform endodontic treatment on children and were excluded from the analysis. The majority of respondents were male (83\%). Most (74.9\%) endodontists worked either in a group practice or as a solo practitioner with the remaining providers practicing in an academic or public health setting. $53.8 \%$ of providers who responded to the survey were in the age range of 36-55 years old and $73.3 \%$ identified as White or Caucasian.

\section{Endodontic Training and Practice}

The frequency of pulpal necrosis, graduate training and CE courses taken by endodontists who perform endodontic treatment on immature permanent teeth are presented in table 3. The frequency of children diagnosed with pulpal necrosis of their permanent immature teeth ranged from $15.6 \%$ (frequently) to $49.5 \%$ (occasionally) 
(Table 3) .Regeneration and apexification procedures were being performed by $53 \%$ of endodontists and $34.5 \%$ of endodontists indicated that they only perform apexification (Table 3). When asked if regenerative endodontics and or apexification were part of their graduate training, $66.5 \%$ indicated that they were not taught regenerative endodontics but only apexification during their residency programs. $53.4 \%$ of endodontists who responded to the survey reported that they did not take any $\mathrm{CE}$ courses in regeneration and apexification. $85.7 \%$ of endodontists indicated that they never refer to another local endodontist or pediatric dentists where as $14.3 \%$ indicated that they sometimes refer (Table 3).

\section{Frequency of Treatment Choice Considerations}

\section{A. Clinical Factors}

When considering evidence base, $60 \%$ of endodontists believe that apexification is the treatment of choice. $77.8 \%$ indicated that apexification was the treatment of choice when considering predictability of outcome (table 4). Regeneration was the preferable treatment option when considering continued root development $(89.0 \%)$ and apical closure (66.7\%) (Table 4)

\section{B. Patient Factors}

Apexification was the preferable treatment option when considering patient compliance (57.3\%), number of required appointments (51.2\%) and likelihood of tooth discoloration (53.3\%) (Table 4). On the other hand, regeneration was the preferable treatment option when considering long term tooth survival (68.5\%) (Table4)

\section{Treatment Choice Considerations Bivariate Analysis}

When considering evidence base, continued root development and long term tooth survival, $\mathrm{CE}$ courses $(\mathrm{p}<0.01)$ and method $(\mathrm{p}<0.01)$ were found to be statistically 
significant (Table 5). CE course $(\mathrm{p}<0.01)$ and age $(\mathrm{p}<0.01)$ were found to be statistically significant when considering apical closure. The method used $(\mathrm{p}<0.01)$, was found to be statistically significant when considering the number of appointments and predictability of outcome. Practice type $(\mathrm{p}=0.01)$, residency training $(\mathrm{p}<0.01)$, age $(\mathrm{p}=0.02)$ and method ( $p<0.01$ ) were found to be statistically significant when considering patient compliance. When considering the likelihood of tooth discoloration, the method used was found to be marginally significant $(\mathrm{p}=0.07)$. The other explanatory variables were not statistically related to the choice of treatment (table 5). Practitioners' age, courses taken during residency and method were the most significant factors when evaluating patient factors (Table 5). When considering most clinical factors, courses taught during residency, CE courses and method used were the most significant factors (Table 5).

\section{Discussion}

To our knowledge, this is the first study that seeks to query endodontists about treatment options for immature permanent teeth with pulpal necrosis. While there have been significant advances in the field of regenerative endodontics as exemplified by the number of publications on this topic, to date no study has sought to understand the factors that affect the decision making process when choosing regenerative endodontics or apexification for the treatment of a necrotic immature permanent tooth. We developed a survey to systematically analyze the perceptions of practicing endodontists on the best treatment options for an immature permanent tooth.

A survey is defined as a brief interaction with a population of individuals about a particular topic of interest. surveys are not merely used for conducting polls but have been shown to be very useful when conducting an experiment that seeks to analyze trends and to determine what the current clinical practice philosophies are [86]. 
Developing a survey for research involves three steps; the survey design, survey instrument development and survey distribution.

To determine the survey design, there are two objectives that need to be met [86]. First, a selection method must be developed to choose the desired sample from the population of interest. Once this has been determined then the desired response rate is established. Endodontists were selected as the desired population of interest because they are the dental providers who would most likely perform endodontic procedures on immature permanent teeth. The states of NY, TX, CA and NC were surveyed not only because of their geographical locations but because these states had the highest number of endodontic training programs. In the year 2000, the number of endodontists in the United States was determined to be $3,816^{[87]}$. With this estimate in mind, a survey which targets 1615 endodontists represents a substantial proportion of the endodontic population. Information gathered from endodontists in these 4 states should therefore be considered to be representative of endodontists in the entire country. Moreover, since this study involved the use of both electronic and paper surveys, it would require a lot more resources to survey the entire country using these methods.

To develop the survey instrument, the focus of the study must first be clearly defined. This focus then needs to be translated into questions for which there are factors that can be measured. A good survey question is one that produces results that are both reliable and valid [88]. Reliability in this context addresses the consistency in measurement and validity refers to the accuracy of measurement. Changes in structure and wording of questions can elicit different responses. Validity is influenced by survey design. Therefore, a valid survey is one that asks questions that meet the study's objective. The words used in the question should be within the scope of the respondent's 
educational background and should be free of bias. The purpose of the survey is not only to provide responses to certain questions but to ensure that the data obtained from the survey can be used to perform statistical analyses. To achieve that purpose, the survey needs to be consistently distributed as errors in distribution can impact data processing.

Most survey research is distributed using one mode of distribution such as a face to face interview, electronic survey, or phone interview. A dual mode of distribution was chosen in this study to increase the number of responses as advocated by Salant and Dillman [86]. Analyses of response rates shows that paper surveys elicit more responses than electronic surveys $[89,90]$. The electronic surveys are used initially due to low cost, ease of access and time[91]. They are then followed by paper surveys to improve the response rate and to give practitioners more time to complete and return the survey.

Our survey questions were developed and then evaluated by a public health specialist to ensure that the questions not only met the objective of the study but to also make certain that the way the questions were asked and responses recorded allowed for easy statistical analysis. Once these objectives were met our survey was pilot tested with a group of endodontic residents and faculty. Survey questions were particularly evaluated for content, wording and clarity. All feedback was taken into consideration and appropriate changes were made. Surveys were then distributed using a dual mode to increase response rate. Qualtrics was used for electronic survey distribution because it allows reminders to be sent, records data in a manner that can be easily obtained for analysis and it allows surveys to be sent anonymously. Teleform was used because it decreases manual data entry and like qualtrics organizes all data in a form that can be easily analyzed. All these factors ensured that our survey was of good quality and would produce valuable results by meeting all of the objectives of a good survey. 


\section{Demographics}

Most of the respondents in our survey were private practice practitioners. What was surprising was the number of endodontists who practiced in a public health setting (26\%) which can be reminiscent of the percentage of endodontic providers who may be Medicaid providers. Access to dental care is a problem in many states and having access to a specialist such as an endodontists in a public health setting is important for children as it is significant that their teeth be saved for as long as possible. The frequency of dental trauma of the immature permanent tooth ranges from 4-66 \% in children ${ }^{[6,7]}$. Pulpal necrosis is the most prevalent post traumatic event to occur (26.9\%) [7]. It was surprising that most responders occasionally or rarely to never saw children diagnosed with pulpal necrosis. This raises an important question- If these children are not being treated by endodontists then are these children not being treated endodontically or are they not being seen by endodontists due to other factors such as behavioral management. One of those questions can be answered with our study. $85.7 \%$ of endodontists indicated that they never refer pediatric patients to another local endodontist or pediatric dentist. If they do not refer patients and occasionally to rarely see children with pulpal necrosis, then we can assume that the frequency by which children are diagnosed with pulpal necrosis and treated is extremely low. Another reason could be that general dentists are treating these children or might be referring them to a local pediatric dentist.

\section{Clinical Factors}

When considering clinical factors, the method of treatment was found to correlate with evidence based research, continued root development and long term tooth survival. It was not surprising that most endodontists chose apexification when 
considering evidence based research and regeneration when considering continued root development and long term tooth survival. There is an abundance of literature that evaluates calcium hydroxide and MTA apexification and a lower number of studies which compare all three treatment options or just regeneration alone. Calcium hydroxide has a very high success rate. Studies have shown that it can range from $90 \%$ to $96 \%{ }^{[1,27,34]}$. This high success rate has also been shown with the use of MTA when used as an apical plug during apexification procedures. However, the literature has indicated that apexification procedures do not strengthen teeth and these teeth can be subjected to tooth fracture [52], [17] [53]. Regeneration has been shown to result in continued root development by increasing the root length and dentin thickness that has resulted in better tooth survival [17], [54],[55], These studies are in agreement with the responses obtained.

$\mathrm{CE}$ courses in addition to the method were found to influence the decision to choose apexification or regeneration when considering evidence based research and continued root development. More than half of the respondents indicated that they did not take any $\mathrm{CE}$ courses in regeneration or apexification. It was surprising that despite the lack of $\mathrm{CE}$ in those respective areas, endodontists still believed that apexification is the treatment of choice when considering evidence based research and that regeneration is the treatment of choice when considering continued root development and long term tooth survival. There are other avenues used for learning such as the endodontic literature, community journal clubs and state dental association meetings including the annual AAE conference. Having access to the Journal of Endodontics (JOE) as an AAE member serves as a reservoir of information filled with current advances in the field of regenerative endodontics. Recently the JOE has incorporated a separate section of the 
journal attributed to only studies in the field of regenerative endodontics. CE may therefore not be as important in this field when it comes to knowledge of the different types of treatment options. The same explanation can be applied to apical closure. Those respondents who did not take any $\mathrm{CE}$ courses in regenerative endodontics or apexification were more likely to choose regeneration for apical closure possibly for the same reasons as described above.

The method of treatment performed was also found to influence the decision to pick regeneration when considering apical closure. Those who performed both regeneration and apexification in their practices were more likely to choose regeneration over apexification. This result is not very surprising because although newer techniques in the field of regenerative endodontics have been recently introduced, most case reports and case series have shown that regeneration results in more apical closure when compared to apexification[54], [56], [57].

In addition to the method, age was also shown to influence the decision to choose regenerative endodontics over apexification when considering apical closure. Most endodontists who responded to the survey were in the age range of $35-55$ but 25\% of responders were in the age group of 56-65. This was surprising because $66.5 \%$ of responders indicated that they were only taught apexification in their graduate training programs. Even though they were only taught apexification, the present literature on the topic has convinced them that regeneration is more likely to result in continued root development. Studies have assessed the quality of the apical barrier formed with apexification which has been shown to be inconsistent resulting in either the formation of a calcified bridge or at times show no signs of closure [36]. On the other hand case studies and case reports have shown that regenerative endodontic procedures can 
successfully heal apical periodontitis and result in an increase in dentin thickness and continued root development [54], [56], [57]. These studies may have convinced practitioners that regeneration is more likely to result in apical closure than apexification.

\section{Patient Factors}

The method used was found to influence the decision to choose one treatment alternative over the other when considering patient compliance, number of required appointments and long term tooth survival. It is not surprising that those who perform both apexification and regeneration were more likely to perceive apexification to be better than regeneration when considering patient compliance. With the introduction of MTA apexification which has been shown to decrease the number of appointments with similar success to calcium hydroxide apexification it is more likely that patients will show up for one or two appointments verses multiple appointments ${ }^{[1,32]}$. It is also not surprising that responders who perform both apexification and regeneration were more likely to choose regeneration when considering long term tooth survival. Many studies have discussed the disadvantages of apexification whether done with calcium hydroxide or MTA as previously described [35, 38, 40-42] [52], [17] [53]. Regeneration has been shown to be more advantageous as it allows to tooth to continue to develop into a mature permanent tooth which increases the likelihood that this tooth will remain in the mouth for a longer period of time [17], [54],[55], [56],[57].

Alternatively, when the number of appointments is considered, more than half of those who perform both apexification and regeneration were more likely to choose apexification as the treatment of choice. As discussed, the introduction of MTA as a material for apexification procedures has decreased the number of appointments. On the other hand, the present protocols for regenerative endodontics involve multiple 
appointments as a perfect protocol has not been established. Therefore since there is a lack of a proper protocol, it cannot be modified to decrease the number of appointments at this time even though one case report has shown successful revascularization using a one step or conservative revascularization protocol [92].

In addition to the method, the courses taken during residency had an influence on both the number of required appointments as well as patient compliance. $66.5 \%$ indicated that they were only taught apexification. These individuals were more likely to pick apexification than regeneration when both factors were considered. Experiences dictate how a provider will run their individual practices and their clinical capabilities with depend on their training during their respective residency programs. A provider who is taught only apexification during residency will be more likely to perform those procedures especially with the advent of MTA apexification which decreases the number of appointments and increases patient compliance.

Age was shown to have an influence on certain patient factors such as patient compliance, long term tooth survival and number of required appointments. Apexification was the preferable choice when considering patient compliance and number of require appointment and regeneration when considering long term tooth survival. We would assume that because a practitioner is older that means that he or she may have been practicing for a longer period of time and will perform more of the procedures taught during their residency training. However, age does not necessarily correlate with the number of years in practice. A practitioner may have been a general dentist for some time or could have changed careers at a later time. It is not surprising that their decisions are dependent on their private practice experiences as well as that obtained in the endodontic literature. 
What is also not surprising is that the majority of responders were in the age group of 36-55 years old and most of them indicated that they were only taught apexification. The average age of a graduate from an endodontic residency program ranges from 28-30 years old [87]. The most commonly used method of regeneration termed revascularization was introduced in a case report by Iwaya and later in 2004 by Banchs and Trope ${ }^{[54,67]}$. This was presented as an alternative treatment for an immature permanent tooth with a necrotic pulp and an apical diameter of $1.1 \mathrm{~mm}$. Since these reports were published, the number of articles published in the field of regenerative endodontics has increased throughout the past fifteen years. Therefore most of these practitioners would have graduated prior to the reintroduction of this revascularization procedure. What is even more surprising is that despite the majority thinking that apexification is more evidenced based, regeneration was perceived to be the treatment of choice when considering long term tooth survival even though there aren't many studies evaluating the long term tooth survival of teeth treated with regenerative endodontics.

When considering other patient factors such as patient compliance, providers practicing in a private practice setting whether as a solo practitioner or a member of a group practice were more likely to choose apexification. These are the providers that are consistently seeing patients on a regular basis and can judge from their own personal experiences that patients may be more compliant when the procedure being presented to them takes less time. Some of the questions that can be asked are whether providers influence the patient's decision to choose apexification over regeneration because of their residency training or are patients not given the treatment option of regenerative endodontics. Another question this raises is are patients still opting to pick apexification 
due to treatment time even though regeneration can result in longer tooth survival. All these questions depend on the practitioner and the way he or she presents the treatment options to a child's parent.

One of the most surprising findings was that despite the lack of CE courses taken in regenerative endodontics or apexification, responders were twice as likely to choose regeneration when considering long term tooth survival. This decision could be based merely on their private practice experiences. The more patients treated with apexification and followed up throughout years in practice can reflect treatment success and more importantly tooth survival. If more children lost a tooth which was treated with apexification and returned to the practice where the original treatment was done, then practitioners would be aware that the long term results of that treatment option would be low when compared to performing regenerative procedures. Although there are very few short term or long term outcome studies on regenerative endodontics, private practice experiences may influence a practitioner's perception when considering long term tooth survival and opting for regenerative endodontics over apexification.

Finally, it was surprising that the method was shown to marginally influence the decision to choose one treatment option over the other when considering likelihood of tooth discoloration. This could be because when the revascularization procedure was introduced, triple antibiotic paste (TAP) was used for canal disinfection. TAP, a mixture of ciprofloxacin, metronidazole and minocycline and has been shown to be very efficacious against endodontic bacteria present in the necrotic root canal system [56, 69-71]. One of the disadvantages of using TAP is staining which is caused by the presence of minocycline [73]. Some case reports have shown that with the use of a double antibiotic paste which lacks minocycline regeneration can be as successful as with the use of a TAP 
[67]. Calcium hydroxide, another intracanal medicament which was once thought to be detrimental to the survival of stem cells has been shown to also be effective in canal disinfection leading to a successful outcome in regenerative endodontics [74]. Staining can also occur due to the presence of MTA used as a coronal seal but a case report with the use of biodentine has been shown to result in a more esthetic result [93]. There are different materials that can be used for regeneration which can decrease the likelihood of staining and this may explain why it did not influence the decision to choose regenerative endodontics or apexification.

\section{Conclusion}

In conclusion based on the results of our study, the method, $\mathrm{CE}$, courses taken during residency, age and practice type were the main factors that influenced an endodontist's decision to choose either regeneration or apexification as their preferable treatment option when considering both patient and clinical factors irrespective of their geographical location.

Table 1. Number of endodontists in each state

\begin{tabular}{|l|l|}
\hline State & Endodontists \\
\hline NY & 312 \\
\hline TX & 268 \\
\hline NC & 169 \\
\hline CA & 866 \\
\hline Total & $\mathbf{1 6 1 5}$ \\
\hline
\end{tabular}


Figure 1. Qualtrics survey responses

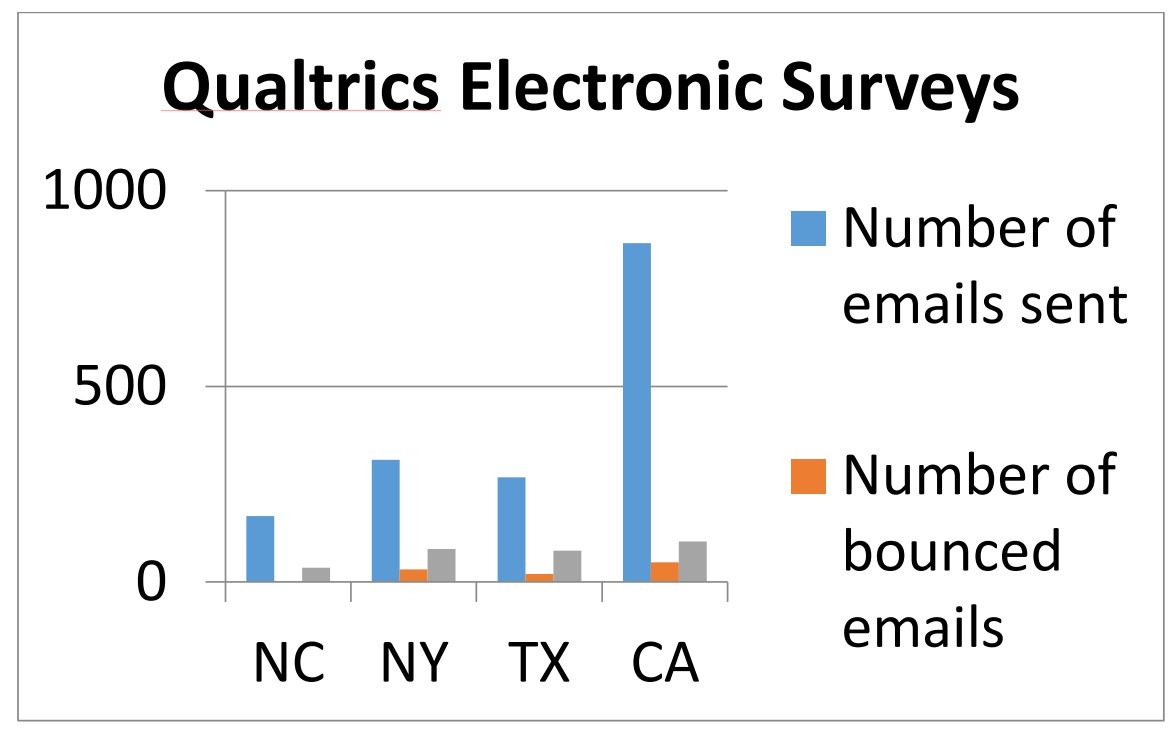




\begin{tabular}{|l|l|l|}
\hline \multicolumn{3}{|l|}{ Table 2: Respondent Demographics } \\
\hline & & \\
\hline Practice Type N=43O & $\mathrm{n}$ & $\%$ \\
\hline Public Health Clinic & 112 & 26.0 \\
\hline Private Practice (group) & 125 & 36.3 \\
\hline Private Practice (solo) & 166 & 38.6 \\
\hline Academia & 27 & 6.3 \\
\hline Location $\mathbf{N}=\mathbf{4 6 4}$ & & \\
\hline CA & 229 & 49.4 \\
\hline NY & 100 & 21.6 \\
\hline TX & 58 & 12.5 \\
\hline NC & 77 & 16.5 \\
\hline Age Group N=461 & & \\
\hline $25-35$ & 46 & 10.0 \\
\hline $36-45$ & 120 & 26.0 \\
\hline $46-55$ & 128 & 27.8 \\
\hline $56-65$ & 114 & 24.7 \\
\hline$>65$ & 53 & 11.5 \\
\hline Gender $\mathbf{N}=\mathbf{4 5 6}$ & 333 & 73.3 \\
\hline Male & 78 & 26.7 \\
\hline Female & 17.1 \\
\hline Race N=454 & & \\
\hline White & & \\
\hline Other & & \\
\hline
\end{tabular}


Table 3: Respondent Percentages - Conditions, Method (treatment performed),frequency of pulpal necrosis and education (Grad course taught and CE)

\begin{tabular}{|c|c|c|c|c|c|c|}
\hline \multicolumn{7}{|c|}{$\begin{array}{l}\text { How often do you see children with pulpa } \\
\text { permanent teeth }\end{array}$} \\
\hline \multirow{3}{*}{$\begin{array}{l}\text { Condition } \\
\text { Necrotic pulp }\end{array}$} & \multicolumn{2}{|c|}{$\begin{array}{l}\text { Frequently (at least } \\
\text { once per month) }\end{array}$} & \multicolumn{2}{|c|}{ Occasionally } & \multicolumn{2}{|c|}{ Rarely to Never } \\
\hline & $\mathrm{n}$ & $\%$ & $\mathrm{n}$ & $\%$ & $\mathrm{n}$ & $\%$ \\
\hline & 72 & 15.6 & 229 & 49.5 & 162 & 35.0 \\
\hline \multicolumn{7}{|c|}{$\begin{array}{l}\text { Please indicate which of the following procedures are being performed } \\
\text { in your practice on young permanent teeth }\end{array}$} \\
\hline \multicolumn{3}{|l|}{ Procedure } & \multicolumn{4}{|l|}{ Yes } \\
\hline & \multicolumn{2}{|l|}{$\mathbf{N}$} & \multicolumn{2}{|l|}{$\%$} \\
\hline \multicolumn{3}{|c|}{ Apexification Only } & \multicolumn{2}{|l|}{147} & \multicolumn{2}{|l|}{34.5} \\
\hline \multicolumn{3}{|c|}{ Regeneration Only } & \multicolumn{2}{|l|}{37} & \multicolumn{2}{|l|}{8.7} \\
\hline \multicolumn{3}{|c|}{$\begin{array}{l}\text { Both Apexification and Regenerative } \\
\text { Endodontics }\end{array}$} & \multicolumn{2}{|l|}{226} & \multicolumn{2}{|l|}{53.1} \\
\hline \multicolumn{3}{|c|}{ Neither } & \multicolumn{2}{|l|}{16} & \multicolumn{2}{|l|}{3.8} \\
\hline \multicolumn{7}{|c|}{$\begin{array}{l}\text { Were you taught regenerative endodontics and or apexification during } \\
\text { your graduate residency program }\end{array}$} \\
\hline \multirow{2}{*}{\multicolumn{3}{|c|}{ Procedure }} & \multicolumn{4}{|l|}{ Yes } \\
\hline & & & \multicolumn{2}{|l|}{$\mathrm{n}$} & \multicolumn{2}{|l|}{$\%$} \\
\hline \multicolumn{3}{|c|}{ Apexification Only } & \multicolumn{2}{|l|}{306} & \multicolumn{2}{|l|}{66.5} \\
\hline \multicolumn{3}{|c|}{ Regenerative Endodontics Only } & \multicolumn{2}{|l|}{2} & \multicolumn{2}{|l|}{0.4} \\
\hline \multicolumn{3}{|c|}{$\begin{array}{l}\text { Both Apexification and Regenerative } \\
\text { Endodontics }\end{array}$} & \multicolumn{2}{|l|}{142} & \multicolumn{2}{|c|}{30.9} \\
\hline
\end{tabular}




\begin{tabular}{|c|c|c|}
\hline Neither & 10 & 2.2 \\
\hline \multicolumn{3}{|c|}{$\begin{array}{l}\text { Have you taken CE courses in regenerative endodontics or } \\
\text { apexification? }\end{array}$} \\
\hline \multirow[t]{2}{*}{ Procedure } & \multicolumn{2}{|l|}{ Yes } \\
\hline & $\mathrm{n}$ & $\%$ \\
\hline Apexification Only & 93 & 20.1 \\
\hline Regenerative Endodontics only & 94 & 20.3 \\
\hline $\begin{array}{l}\text { Both Apexification and Regenerative } \\
\text { Endodontics }\end{array}$ & 29 & 6.3 \\
\hline Neither & 247 & 53.4 \\
\hline \multicolumn{3}{|c|}{$\begin{array}{l}\text { Refer In the past } 6 \text { months how often have you referred pediatric } \\
\text { patients and young adults to a local endodontist or pediatric dentist for } \\
\text { endodontic care of an immature permanent tooth }\end{array}$} \\
\hline & $\mathrm{n}$ & $\%$ \\
\hline Never & 353 & 85.7 \\
\hline Sometimes & 59 & 14.3 \\
\hline
\end{tabular}

Table4: Preferable Choice of treatment

\begin{tabular}{|c|c|c|c|c|}
\hline $\begin{array}{l}\text { When considering } \\
\text { permanent tooth (a) } \\
\text { treatment do you th } \\
\text { the following }\end{array}$ & $\begin{array}{l}\text { cho } \\
\text { xific } \\
\text { k is }\end{array}$ & $\begin{array}{l}\text { reatr } \\
\text { s reg } \\
\text { ble v }\end{array}$ & or at & $\begin{array}{l}\text { ture } \\
\text { each of }\end{array}$ \\
\hline & Ape & & $\operatorname{Reg}$ & \\
\hline Clinical Factors & $\mathrm{n}$ & $\%$ & $\mathrm{~N}$ & $\%$ \\
\hline Evidence Base $\mathrm{N}=433$ & 260 & 60.0 & 173 & 40.0 \\
\hline $\begin{array}{l}\text { Predictability of } \\
\text { Outcome } N=441\end{array}$ & 343 & 77.8 & 98 & 22.2 \\
\hline
\end{tabular}




\begin{tabular}{|l|l|l|l|l|}
\hline $\begin{array}{l}\text { Continued root } \\
\text { development N=446 }\end{array}$ & 49 & 11.0 & 397 & 89.0 \\
\hline Apical Closure N=426 & 147 & 33.3 & 295 & 66.7 \\
\hline Patient Factors & $\mathrm{n}$ & $\%$ & $\mathrm{~N}$ & $\%$ \\
\hline $\begin{array}{l}\text { Patient Compliance } \\
\mathrm{N}=426\end{array}$ & 244 & 57.3 & 182 & 42.7 \\
\hline $\begin{array}{l}\text { Number of } \\
\text { appointments required } \\
\text { N=432 }\end{array}$ & 221 & 51.2 & 211 & 48.8 \\
\hline $\begin{array}{l}\text { Long term tooth } \\
\text { survival N=426 }\end{array}$ & 134 & 31.5 & 292 & 68.5 \\
\hline $\begin{array}{l}\text { Likelihood of tooth } \\
\text { discoloration N=411 }\end{array}$ & 219 & 53.3 & 192 & 46.7 \\
\hline
\end{tabular}

Table 5: Chi-square- Comparison factors and associated variables

\begin{tabular}{|c|c|c|}
\hline & $\begin{array}{l}\text { Explanatory } \\
\text { Variables }\end{array}$ & $\begin{array}{l}\mathrm{P}- \\
\text { value }\end{array}$ \\
\hline \multicolumn{3}{|l|}{$\begin{array}{l}\text { Patient } \\
\text { Factors }\end{array}$} \\
\hline \multirow[t]{2}{*}{$\begin{array}{l}\text { Likelihood of } \\
\text { tooth } \\
\text { discoloration }\end{array}$} & & \\
\hline & $\begin{array}{l}\text { Method (Regen } \\
\text { vs Apex) }\end{array}$ & 0.07 \\
\hline \multicolumn{3}{|l|}{$\begin{array}{l}\text { Patient } \\
\text { compliance }\end{array}$} \\
\hline & age & 0.02 \\
\hline
\end{tabular}




\begin{tabular}{|c|c|c|}
\hline & Practice type & 0.01 \\
\hline & $\begin{array}{l}\text { Courses taught } \\
\text { during } \\
\text { residency }\end{array}$ & $<0.01$ \\
\hline & $\begin{array}{l}\text { Method (Regen } \\
\text { vs Apex) }\end{array}$ & $<0.01$ \\
\hline \multirow[t]{4}{*}{$\begin{array}{l}\text { Number of } \\
\text { required } \\
\text { appointments }\end{array}$} & & \\
\hline & age & 0.01 \\
\hline & $\begin{array}{l}\text { Courses taught } \\
\text { during } \\
\text { residency }\end{array}$ & 0.04 \\
\hline & $\begin{array}{l}\text { Method (Regen } \\
\text { vs Apex) }\end{array}$ & $<0.01$ \\
\hline \multirow[t]{4}{*}{$\begin{array}{l}\text { Long term } \\
\text { tooth survival }\end{array}$} & & \\
\hline & age & 0.03 \\
\hline & CE courses & $<0.01$ \\
\hline & $\begin{array}{l}\text { Method (Regen } \\
\text { vs Apex) }\end{array}$ & $<0.01$ \\
\hline \multicolumn{3}{|l|}{$\begin{array}{l}\text { Clinical } \\
\text { Factors }\end{array}$} \\
\hline \multirow[t]{4}{*}{$\begin{array}{l}\text { Evidenced } \\
\text { based }\end{array}$} & & \\
\hline & $\begin{array}{l}\text { Courses taught } \\
\text { during } \\
\text { residency }\end{array}$ & 0.02 \\
\hline & CE Courses & $<0.01$ \\
\hline & Method (Regen & $<0.01$ \\
\hline
\end{tabular}




\begin{tabular}{|l|l|l|}
\hline & vs Apex) & \\
\hline $\begin{array}{l}\text { Predictability } \\
\text { of Outcome }\end{array}$ & $\begin{array}{l}\text { Courses taught } \\
\text { during } \\
\text { residency }\end{array}$ & 0.04 \\
\hline & $\begin{array}{l}\text { Method (Regen } \\
\text { vs Apex) }\end{array}$ & $<0.01$ \\
\hline $\begin{array}{l}\text { Continued } \\
\text { Root } \\
\text { development }\end{array}$ & CE Courses & $<0.01$ \\
\hline & $\begin{array}{l}\text { Method (Regen } \\
\text { vs Apex) }\end{array}$ & $<0.01$ \\
\hline & age & $<0.01$ \\
\hline $\begin{array}{l}\text { Apical } \\
\text { closure }\end{array}$ & CE Courses & $<0.01$ \\
\hline & $\begin{array}{l}\text { Method (Regen } \\
\text { vs Apex) }\end{array}$ & 0.02 \\
\hline & & \\
\hline & & \\
\hline
\end{tabular}




\section{Survey Instrument}

Do you provide endodontic care to children and adolescents?

$\mathrm{O}$ Yes

O No

If No Is Selected, Then Skip To End of Survey

Please indicate which of the following procedures are being performed in your practice on young permanent teeth (Click all that apply)

Apexification (D3351-D3354)

Regeneration (D3355-D3357)

Neither

How often do you see children with pulpal necrosis of their immature permanent teeth?

O Multiple times a week

O Few times a month

O Seldom

O Rarely

O Never

Were you taught regenerative endodontics and or apexification during your graduate residency program?

O Neither regenerative endodontics nor apexification

O Both regenerative endodontics and apexification

O Regeneration Endodontics only

O Apexification only

Have you taken continuing education courses in the field of regenerative endodontics or apexification? Please select one

O I have not taken CE courses in regenerative endodontics or apexification

O I have taken $\mathrm{CE}$ courses in both regenerative endodontics and apexification

O I have taken $\mathrm{CE}$ courses in regenerative endodontics

O I have taken CE courses in apexification 
When considering the choice of treatment for an immature permanent tooth (apexification vs regeneration), which treatment do you think is preferable when considering each of the following

\begin{tabular}{|c|c|c|}
\hline & Apexification (1) & Regeneration (2) \\
\hline Evidenced Based & 0 & 0 \\
$\begin{array}{c}\text { Likelihood of tooth } \\
\text { discoloration }\end{array}$ & 0 & 0 \\
Patient Compliance & 0 & 0 \\
Number of Appointments & 0 & 0 \\
$\begin{array}{c}\text { Continued root } \\
\text { development }\end{array}$ & 0 & 0 \\
Apical closure & 0 & 0 \\
Long term tooth survival & 0 & 0 \\
\hline
\end{tabular}

What year did you graduate from dental school? (DDS/DMD or equivalent)

Refer In the past 6 months how often have you referred pediatric patients and young adults to a local endodontist or pediatric dentist for endodontic care of an immature permanent tooth

\begin{tabular}{|c|c|c|c|c|}
\hline & Never (1) & $\begin{array}{c}\text { Less than Once } \\
\text { a Month (2) }\end{array}$ & $\begin{array}{c}\text { At LeastOnce a } \\
\text { Month (3) }\end{array}$ & $\begin{array}{c}\text { At Least once } \\
\text { per week (4) }\end{array}$ \\
\hline $\begin{array}{c}\text { Local Pediatric } \\
\text { Dentist (1) }\end{array}$ & 0 & 0 & 0 & 0 \\
\hline
\end{tabular}


What is your race?

O Multi-racial

O Black

O White

O Asian

O Pacific Islander

O No response

O Other

What best describes your pactice type?

O Private Practice-Solo Practice

O Private Practice- Group Practice

O Academia

O Public Health/ Community Dental Care or Healh Center/ Special Care Health Center O Other

What is your age group?
O 25-35
O $36-45$
O $46-55$
O $56-65$
O 65 and older

In what geographic location do you practice?

O United States: North East

O United States: South East

O United States: Mid West

O United States: South West

O United States: North West

What is your gender?

O Male

O Female 


\section{REFERENCES}

1. Witherspoon, D.E. and K. Ham, One-visit apexification: technique for inducing root-end barrier formation in apical closures. Pract Proced Aesthet Dent, 2001. 13(6): p. 455-60; quiz 462.

2. $\quad$ Arens, D.E., Treatment of the incompletely formed tooth. Ill Dent J, 1978. 47(3): p. 110-6.

3. Op Heij, D.G., et al., Age as compromising factor for implant insertion. Periodontol 2000, 2003. 33: p. 172-84.

4. Moorrees, C.F., E.A. Fanning, and E.E. Hunt, Jr., Age Variation of Formation Stages for Ten Permanent Teeth. J Dent Res, 1963. 42: p. 1490-502.

5. $\quad$ Mason, C., et al., A retrospective study of unerupted maxillary incisors associated with supernumerary teeth. Br J Oral Maxillofac Surg, 2000. 38(1): p. $62-5$.

6. Andreasen, J.O., Etiology and pathogenesis of traumatic dental injuries. A clinical study of 1,298 cases. Scand J Dent Res, 1970. 78(4): p. 329-42.

7. Hecova, H., et al., A retrospective study of 889 injured permanent teeth. Dent Traumatol, 2010. 26(6): p. 466-75.

8. Andreasen, J.O. and J.J. Ravn, Epidemiology of traumatic dental injuries to primary and permanent teeth in a Danish population sample. Int J Oral Surg, 1972. 1(5): p. 235-9.

9. Borum, M.K. and J.O. Andreasen, Therapeutic and economic implications of traumatic dental injuries in Denmark: an estimate based on 7549 patients treated at a major trauma centre. Int J Paediatr Dent, 2001. 11(4): p. 249-58.

10. Andreasen, J.O., et al., Replantation of 400 avulsed permanent incisors. 4. Factors related to periodontal ligament healing. Endod Dent Traumatol, 1995. 11(2): p. 76-89.

11. Nikoui, M., D.J. Kenny, and E.J. Barrett, Clinical outcomes for permanent incisor luxations in a pediatric population. III. Lateral luxations. Dent Traumatol, 2003. 19(5): p. 280-5.

12. Izumi, T., et al., Immunohistochemical study on the immunocompetent cells of the pulp in human non-carious and carious teeth. Arch Oral Biol, 1995. 40(7): p. 609-14.

13. Brannstrom, M. and P.O. Lind, Pulpal response to early dental caries. J Dent Res, 1965. 44(5): p. 1045-50. 
14. Reeves, R. and H.R. Stanley, The relationship of bacterial penetration and pulpal pathosis in carious teeth. Oral Surg Oral Med Oral Pathol, 1966. 22(1): p. $59-65$.

15. Bergenholtz, G., Inflammatory response of the dental pulp to bacterial irritation. J Endod, 1981. 7(3): p. 100-4.

16. Gutmann, J.L. and J.F. Heaton, Management of the open (immature) apex. 1. Vital teeth. Int Endod J, 1981. 14(3): p. 166-72.

17. Jeeruphan, T., et al., Mahidol study 1: comparison of radiographic and survival outcomes of immature teeth treated with either regenerative endodontic or apexification methods: a retrospective study. J Endod, 2012. 38(10): p. 1330-6.

18. Webber, R.T., Apexogenesis versus apexification. Dent Clin North Am, 1984. 28(4): p. 669-97.

19. Hilton, T.J., Keys to clinical success with pulp capping: a review of the literature. Oper Dent, 2009. 34(5): p. 615-25.

20. Thompson, V., et al., Treatment of deep carious lesions by complete excavation or partial removal: a critical review. J Am Dent Assoc, 2008. 139(6): p. 705-12.

21. Mertz-Fairhurst, E.J., G.S. Schuster, and C.W. Fairhurst, Arresting caries by sealants: results of a clinical study. J Am Dent Assoc, 1986. 112(2): p. 194-7.

22. Mertz-Fairhurst, E.J., et al., Clinical performance of sealed composite restorations placed over caries compared with sealed and unsealed amalgam restorations. J Am Dent Assoc, 1987. 115(5): p. 689-94.

23. Mertz-Fairhurst, E.J., et al., Ultraconservative and cariostatic sealed restorations: results at year 10. J Am Dent Assoc, 1998. 129(1): p. 55-66.

24. Watts, A. and R.C. Paterson, Bacterial contamination as a factor influencing the toxicity of materials to the exposed dental pulp. Oral Surg Oral Med Oral Pathol, 1987. 64(4): p. 466-74.

25. Baume, L.J. and J. Holz, Long term clinical assessment of direct pulp capping . Int Dent J, 1981. 31(4): p. 251-60.

26. Costa, C.A., C.A. Edwards, and C.T. Hanks, Cytotoxic effects of cleansing solutions recommended for chemical lavage of pulp exposures. Am J Dent, 2001. 14(1): p. 25-30.

27. Cvek, M., A clinical report on partial pulpotomy and capping with calcium hydroxide in permanent incisors with complicated crown fracture. J Endod, 1978. 4(8): p. 232-7. 
28. Aguilar, P. and P. Linsuwanont, Vital pulp therapy in vital permanent teeth with cariously exposed pulp: a systematic review. J Endod, 2011. 37(5): p. 581-7.

29. Vargas, K.G., B. Packham, and D. Lowman, Preliminary evaluation of sodium hypochlorite for pulpotomies in primary molars. Pediatr Dent, 2006. 28(6): p. 511-7.

30. Rafter, M., Apexification: a review. Dent Traumatol, 2005. 21(1): p. 1-8.

31. Shabahang, S., et al., A comparative study of root-end induction using osteogenic protein-1, calcium hydroxide, and mineral trioxide aggregate in dogs. J Endod, 1999. 25(1): p. 1-5.

32. Witherspoon, D.E., et al., Retrospective analysis of open apex teeth obturated with mineral trioxide aggregate. J Endod, 2008. 34(10): p. 1171-6.

33. Attalla, M.N. and A.A. Noujaim, Role of calcium hydroxide in the formation of reparative dentine. J Can Dent Assoc (Tor), 1969. 35(5): p. 267-9.

34. Cvek, M., Treatment of non-vital permanent incisors with calcium hydroxide. I. Follow-up of periapical repair and apical closure of immature roots. Odontol Revy, 1972. 23(1): p. 27-44.

35. Abbott, P.V., Apexification with calcium hydroxide--when should the dressing be changed? The case for regular dressing changes. Aust Endod J, 1998. 24(1): p. 27-32.

36. Frank, A.L., Therapy for the divergent pulpless tooth by continued apical formation. J Am Dent Assoc, 1966. 72(1): p. 87-93.

37. El-Meligy, O.A. and D.R. Avery, Comparison of apexification with mineral trioxide aggregate and calcium hydroxide. Pediatr Dent, 2006. 28(3): p. 24853 .

38. Felippe, M.C., et al., The effect of the renewal of calcium hydroxide paste on the apexification and periapical healing of teeth with incomplete root formation. Int Endod J, 2005. 38(7): p. 436-42.

39. Cvek, M. and B. Sundstrom, Treatment of non-vital permanent incisors with calcium hydroxide. V. Histologic appearance of roentgenographically demonstrable apical closure of immature roots. Odontol Revy, 1974. 25(4): p. 379-91.

40. Andreasen, J.O., B. Farik, and E.C. Munksgaard, Long-term calcium hydroxide as a root canal dressing may increase risk of root fracture. Dent Traumatol, 2002. 18(3): p. 134-7. 
41. Grigoratos, D., et al., Effect of exposing dentine to sodium hypochlorite and calcium hydroxide on its flexural strength and elastic modulus. Int Endod J, 2001. 34(2): p. 113-9.

42. Sheehy, E.C. and G.J. Roberts, Use of calcium hydroxide for apical barrier formation and healing in non-vital immature permanent teeth: a review. $\mathrm{Br}$ Dent J, 1997. 183(7): p. 241-6.

43. Cvek, M., Prognosis of luxated non-vital maxillary incisors treated with calcium hydroxide and filled with gutta-percha. A retrospective clinical study. Endod Dent Traumatol, 1992. 8(2): p. 45-55.

44. Torabinejad, M., et al., Physical and chemical properties of a new root-end filling material. J Endod, 1995. 21(7): p. 349-53.

45. Holland, R. and V. de Souza, Ability of a new calcium hydroxide root canal filling material to induce hard tissue formation. J Endod, 1985. 11(12): p. 53543 .

46. Parirokh, M. and M. Torabinejad, Mineral trioxide aggregate: a comprehensive literature review--Part III: Clinical applications, drawbacks, and mechanism of action. J Endod, 2010. 36(3): p. 400-13.

47. Torabinejad, M., et al., Dye leakage of four root end filling materials: effects of blood contamination. J Endod, 1994. 20(4): p. 159-63.

48. Torabinejad, M., et al., Cytotoxicity of four root end filling materials. J Endod, 1995. 21(10): p. 489-92.

49. Torabinejad, M., et al., Comparative investigation of marginal adaptation of mineral trioxide aggregate and other commonly used root-end filling materials. J Endod, 1995. 21(6): p. 295-9.

50. Chala, S., R. Abouqal, and S. Rida, Apexification of immature teeth with calcium hydroxide or mineral trioxide aggregate: systematic review and meta-analysis. Oral Surg Oral Med Oral Pathol Oral Radiol Endod, 2011. 112(4): p. e36-42.

51. Pradhan, D.P., et al., Comparative evaluation of endodontic management of teeth with unformed apices with mineral trioxide aggregate and calcium hydroxide. J Dent Child (Chic), 2006. 73(2): p. 79-85.

52. Bose, R., P. Nummikoski, and K. Hargreaves, A retrospective evaluation of radiographic outcomes in immature teeth with necrotic root canal systems treated with regenerative endodontic procedures. J Endod, 2009. 35(10): p. 1343-9. 
53. Hargreaves, K.M., A. Diogenes, and F.B. Teixeira, Treatment options: biological basis of regenerative endodontic procedures. Pediatr Dent, 2013. 35(2): p. 12940 .

54. Banchs, F. and M. Trope, Revascularization of immature permanent teeth with apical periodontitis: new treatment protocol? J Endod, 2004. 30(4): p. 196200.

55. Chueh, L.H. and G.T. Huang, Immature teeth with periradicular periodontitis or abscess undergoing apexogenesis: a paradigm shift. J Endod, 2006. 32(12): p. 1205-13.

56. Jung, I.Y., S.J. Lee, and K.M. Hargreaves, Biologically based treatment of immature permanent teeth with pulpal necrosis: a case series. Tex Dent J, 2012. 129(6): p. 601-16.

57. Shah, N., et al., Efficacy of revascularization to induce apexification/apexogensis in infected, nonvital, immature teeth: a pilot clinical study. J Endod, 2008. 34(8): p. 919-25; Discussion 1157.

58. Murray, P.E., F. Garcia-Godoy, and K.M. Hargreaves, Regenerative endodontics: a review of current status and a call for action. J Endod, 2007. 33(4): p. 377-90.

59. Ostby, B.N., The role of the blood clot in endodontic therapy. An experimental histologic study. Acta Odontol Scand, 1961. 19: p. 324-53.

60. Nygaard-Ostby, B. and O. Hjortdal, Tissue formation in the root canal following pulp removal. Scand J Dent Res, 1971. 79(5): p. 333-49.

61. Hargreaves, K.M., et al., Regeneration potential of the young permanent tooth: what does the future hold? J Endod, 2008. 34(7 Suppl): p. S51-6.

62. Nosrat, A., A. Seifi, and S. Asgary, Regenerative endodontic treatment (revascularization) for necrotic immature permanent molars: a review and report of two cases with a new biomaterial. J Endod, 2011. 37(4): p. 562-7.

63. Mao, J.J., et al., Regenerative endodontics: barriers and strategies for clinical translation. Dent Clin North Am, 2012. 56(3): p. 639-49.

64. Torabinejad, M. and H. Faras, A clinical and histological report of a tooth with an open apex treated with regenerative endodontics using platelet-rich plasma. J Endod, 2012. 38(6): p. 864-8.

65. Ham, K.A., et al., Preliminary evaluation of BMP-2 expression and histological characteristics during apexification with calcium hydroxide and mineral trioxide aggregate. J Endod, 2005. 31(4): p. 275-9. 
66. Kim, S.G., et al., Effects of growth factors on dental stem/progenitor cells. Dent Clin North Am, 2012. 56(3): p. 563-75.

67. Iwaya, S.I., M. Ikawa, and M. Kubota, Revascularization of an immature permanent tooth with apical periodontitis and sinus tract. Dent Traumatol, 2001. 17(4): p. 185-7.

68. Kling, M., M. Cvek, and I. Mejare, Rate and predictability of pulp revascularization in therapeutically reimplanted permanent incisors. Endod Dent Traumatol, 1986. 2(3): p. 83-9.

69. Hoshino, E., et al., In-vitro antibacterial susceptibility of bacteria taken from infected root dentine to a mixture of ciprofloxacin, metronidazole and minocycline. Int Endod J, 1996. 29(2): p. 125-30.

70. Sato, I., et al., Sterilization of infected root-canal dentine by topical application of a mixture of ciprofloxacin, metronidazole and minocycline in situ. Int Endod J, 1996. 29(2): p. 118-24.

71. Windley, W., 3rd, et al., Disinfection of immature teeth with a triple antibiotic paste. J Endod, 2005. 31(6): p. 439-43.

72. $\quad$ Ding, R.Y., et al., Pulp revascularization of immature teeth with apical periodontitis: a clinical study. J Endod, 2009. 35(5): p. 745-9.

73. Kim, J.H., et al., Tooth discoloration of immature permanent incisor associated with triple antibiotic therapy: a case report. J Endod, 2010. 36(6): p. 1086-91.

74. Cehreli, Z.C., et al., Regenerative endodontic treatment (revascularization) of immature necrotic molars medicated with calcium hydroxide: a case series. J Endod, 2011. 37(9): p. 1327-30.

75. $\quad$ Ring, K.C., et al., The comparison of the effect of endodontic irrigation on cell adherence to root canal dentin. J Endod, 2008. 34(12): p. 1474-9.

76. Galler, K.M., et al., Dentin conditioning codetermines cell fate in regenerative endodontics. J Endod, 2011. 37(11): p. 1536-41.

77. Flake, N.M., et al., A standardized novel method to measure radiographic root changes after endodontic therapy in immature teeth. J Endod, 2014. 40(1): p. 46-50.

78. Dylewski, J.J., Apical closure of nonvital teeth. Oral Surg Oral Med Oral Pathol, 1971. 32(1): p. 82-9. 
79. Ghose, L.J., V.S. Baghdady, and Y.M. Hikmat, Apexification of immature apices of pulpless permanent anterior teeth with calcium hydroxide. J Endod, 1987. 13(6): p. 285-90.

80. Huang, G.T., et al., Stem/progenitor cell-mediated de novo regeneration of dental pulp with newly deposited continuous layer of dentin in an in vivo model. Tissue Eng Part A, 2010. 16(2): p. 605-15.

81. Green, T.L., et al., Radiographic and histologic periapical findings of root canal treated teeth in cadaver. Oral Surg Oral Med Oral Pathol Oral Radiol Endod, 1997. 83(6): p. 707-11.

82. Petrino, J.A., et al., Challenges in regenerative endodontics: a case series. $\mathrm{J}$ Endod, 2010. 36(3): p. 536-41.

83. Epelman, I., et al., A practitioner survey of opinions toward regenerative endodontics. J Endod, 2009. 35(9): p. 1204-10.

84. Manguno, C., et al., A survey of dental residents' expectations for regenerative endodontics. J Endod, 2012. 38(2): p. 137-43.

85. Utneja, S., et al., A survey of attitude and opinions of endodontic residents towards regenerative endodontics. J Conserv Dent, 2013. 16(4): p. 314-8.

86. Salant, P.D., D. A., How to Conduct Your Own Survey. 1994, New York: Wiley: Wiley

87. Brown LJ, N.K., Johns BA, Warren M, The economics of endodontics. 2003.

88. Fowler, F.J., Improving Survey Questions: Design and Evaluation. 1995 38.

89. Ogier, J., The response rates for online surveys - a hit and miss affair. Paper presented at the 2005 Australasian Evaluations Forum: University learning and teaching: Evaluating and enhancing the experience., UNSW, Sydney. 2005: p. 28-29.

90. Ballantyne, C., Moving student evaluation of teaching online: Reporting pilot outcomes and issues with a focus on how to increase student response rate. 2005: p. 28-29.

91. Wright, K.B., Researching Internet-Based Populations: Advantages and Disadvantages of Online Survey Research, Online Questionnaire Authoring Software Packages, and Web Survey Services. Journal of Computer-Mediated Communication, 2005 . 
92. Shin, S.Y., J.S. Albert, and R.E. Mortman, One step pulp revascularization treatment of an immature permanent tooth with chronic apical abscess: a case report. Int Endod J, 2009. 42(12): p. 1118-26.

93. Valles, M., et al., Influence of light and oxygen on the color stability of five calcium silicate-based materials. J Endod, 2013. 39(4): p. 525-8.

94. Kelley, K., et al., Good practice in the conduct and reporting of survey research. Int J Qual Health Care, 2003. 15(3): p. 261-6. 


\section{Section UI}

\section{Conclusion}

Survey research is an important aspect of science and in some cases may not be held to the same standards as basic science or clinical research. The reason for this is that some believe that survey research is easy. Survey research is easy when the survey instrument is poorly developed and produces results that are not valid. A good quality survey with a clear objective is one that can address key issues both in basic science and clinical aspects of the field being investigated. A survey is held to a high standard when it produces results that are reliable [94]. The purpose of a survey is to collect information from a sample of a population that is being investigated in order to draw conclusions that can be extrapolated to the wider population. It is important to understand that survey research is not a method but a form of research approach. Survey research methods include questionnaires, telephone interviews and face to face interviews [94]. This distinction between the methodology and the research approach is not easily understood which can be one reason why some fail to realize the importance of survey research. Survey research is not without its challenges. Because it is not highly regarded, funding can be difficult. Obtaining the necessary funding for this project was extremely challenging. Two grants were written and both rejected because the reviewers did not believe that there was any value in this project. Millions of dollars have been awarded for research grants in the field of regenerative endodontics. Most of these studies are investigating different scaffolds, different protocols and other ways of enhancing the regenerative capabilities of an immature permanent tooth. These areas are extremely 
important and worth investigating, however, if practitioners are not performing these procedures even though they perceive it as being better then this is an area that needs to be addressed.

Some of the ways that we can address this discrepancy between regenerative endodontic research and what is being done clinically is to encourage providers to take $\mathrm{CE}$ courses in regenerative endodontics. However, the results of this study have surprisingly shown that more than $50 \%$ of practitioners deny taking CE courses in regeneration or apexification. Despite this, they seem to be quite knowledgeable of the current evidence available for both treatment options and are able to make valid decisions when deciding which treatment option should be used. The lack of $\mathrm{CE}$ can be explained by techniques used for either treatment option. Apexification and current revascularization techniques are not very challenging for skilled endodontists when compared to techniques utilized during retreatment cases and finding and instrumenting calcified canals. They may not see the value in taking CE courses when it is not technique oriented and would prefer to gain knowledge in those areas at their own convenience. As a member of the AAE, every endodontist will receive a copy of the Journal of Endodontics (JOE) which gives them free access to an abundance of studies. They may decide that they can take CE course in other areas that may not be easily accessible.

Another surprising finding in this study was that endodontists occasionally to rarely diagnose and treat children with pulpal necrosis. Most indicated that they almost never refer. If they are not referring then are general dentists not making the referral or are these children being treated by a pediatric dentist. Some dental providers do not like treating kids due to behavioral management issues especially when a procedure can take 
multiple appointments. If the pediatric dentists are receiving these referrals more than the endodontists then behavioral management may be a topic of interest. If endodontists are having difficulty with behavioral management then having CE courses in that area can help achieve a better clinical experience for both the practitioner and the patient as this may not be addressed during residency training. If $\mathrm{CE}$ courses are not available in this area then the AAE should make these courses available. The next question is whether or not practitioners will sign up for these courses or continue to take other courses that may strengthen other areas in their clinical practice. If an endodontist does not understand the concepts because they were not formally trained in that area then the likelihood of them using it in their respective practices is low. Some of us might be resistant to change especially when our current clinical practice has worked well for years. Despite this, we as healthcare providers need to understand that learning does not end with graduation but continues throughout our lifetime as a health care provider. Since we are able to choose which courses we attend, it is imperative that we not limit ourselves to only one subject of study but to other areas in the field. Most practitioners choose to attend CE courses that may strengthen or expedite their normal clinical practices. By doing so they are limiting their access to clinical advances in the field.

The main goal of endodontics is to save the natural dentition while treating or preventing apical periodontitis. It is vital that children keep their permanent teeth throughout their entire life span. When a child loses a tooth at an early age, that child can have psychological issues because options for tooth replacement are limited. Implant placement is contraindicated in children and depending on the location of the tooth, these children as they age can develop malocclusions and the probability that the 
area of tooth loss can result in a bony defect that makes future implant placement difficult. What are these children supposed to do when they are being bullied because of their smile and they lack confidence because tooth loss has resulted in a low selfesteem? When deciding between regeneration and apexification, it is essential that practitioners pick a treatment option that will not only address the etiology of the problem but will allow that tooth to stay in the mouth for an extended period of time ranging from the age where a child is old enough to get an implant to their entire life span.

In conclusion, survey research was the appropriate research approach for answering the question of how do providers perceive different factors when deciding between regenerative endodontics and apexification. The main goal is to prevent infection and save teeth while enhancing the functionality and survivability of an immature permanent tooth to allow continued root development. As a health care provider, it is our responsibility to meet these objectives and to choose the best treatment option for each child. 